\title{
Geographic Information System (GIS)
}

Emergency Support for the

May 2000 Cerro Grande Wildfire,

Los Alamos, New Mexico, USA

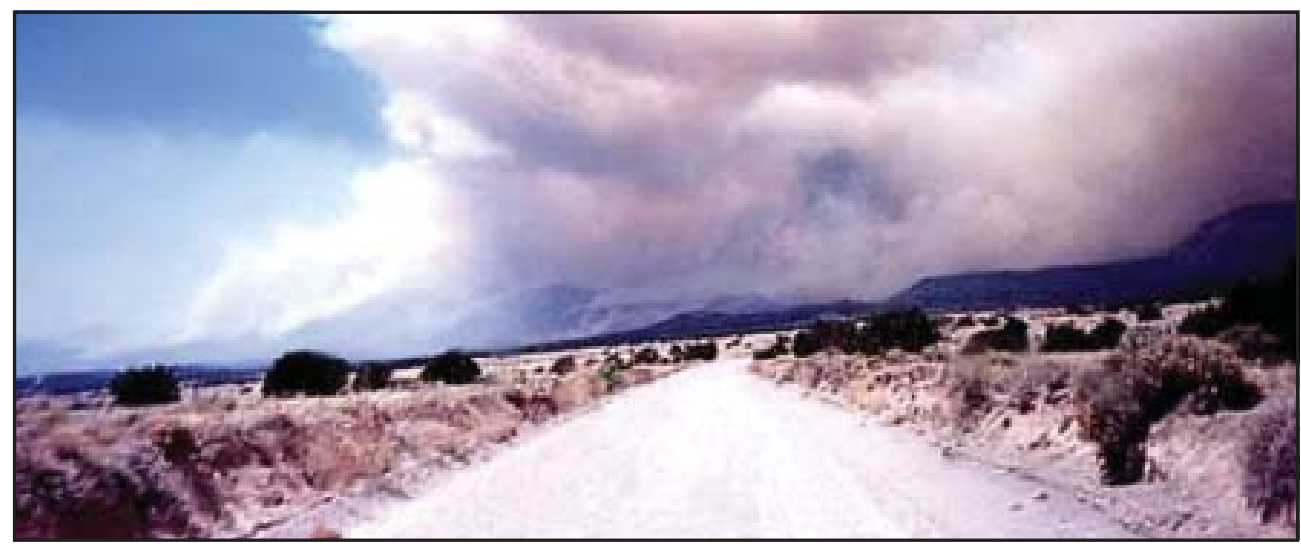


Cover: The view of the Jemez Mountains is nearly obscured by the massive plume of the Cerro Grande wildfire (USFS).

Los Alamos National Laboratory, an affirmative action/equal opportunity employer, is operated by the University of California for the United States Department of Energy under contract W-7405-ENG-36.

This report was prepared as an account of work sponsored by an agency of the United States Government. Neither the Regents of the University of California, the United States Government nor any agency thereof, nor any of their employees make any warranty, express or implied, or assume any legal liability or responsibility for the accuracy, completeness, or usefulness of any information, apparatus, product, or process disclosed, or represent that its use would not infringe privately owned rights. Reference herein to any specific commercial product, process, or service by trade name, trademark, manufacturer, or otherwise does not necessarily constitute or imply its endorsement, recommendation, or favoring by the Regents of the University of California, the United States Government, or any agency thereof. The views and opinions of authors expressed herein do not necessarily state or reflect those of the Regents of the University of California, the United States Government, or any agency thereof. Los Alamos National Laboratory strongly supports academic freedom and a researcher's right to publish; as an institution, however, the Laboratory does not endorse the viewpoint of a publication or guarantee its technical correctness. 
LA-14007-MS

Issued: May 2003

\section{Geographic Information System (GIS)}

Emergency Support for the

May 2000 Cerro Grande Wildfire,

Los Alamos, New Mexico, USA

C. Randall Mynard

Gordon N. Keating

Paul M. Rich

Denise R. Bleakly*

*Sandia National Laboratories

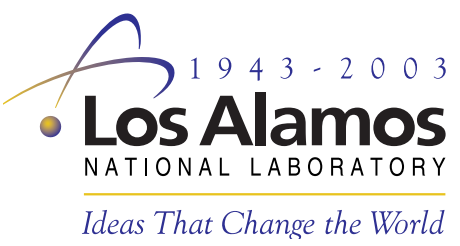




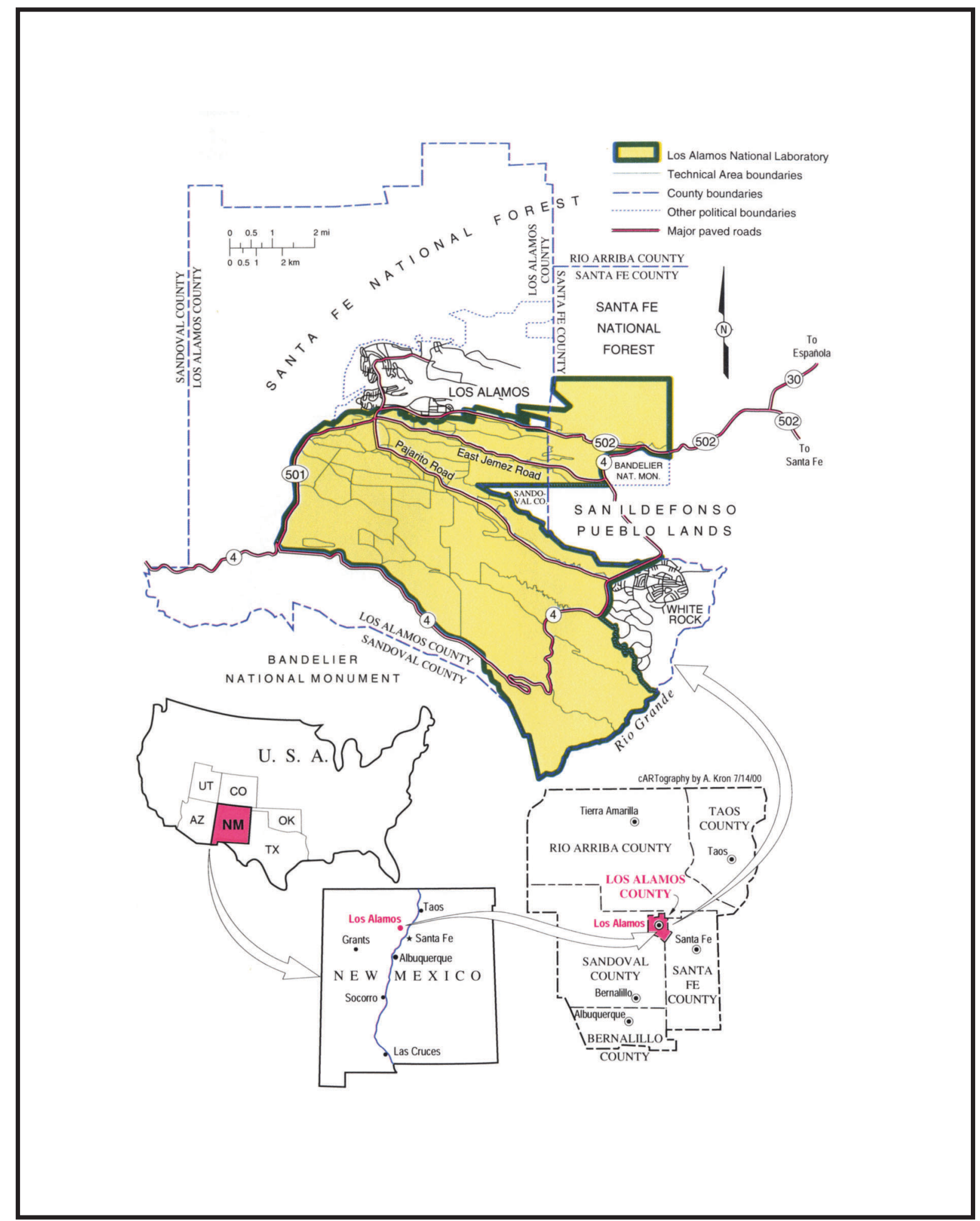

Fig. 1 - Location of Los Alamos National Laboratory. From Environmental Surveillance at Los Alamos during 2001. (LANL Environmental Surveillance Program, 2002). 


\section{CONTENTS}

1.0 Introduction 10

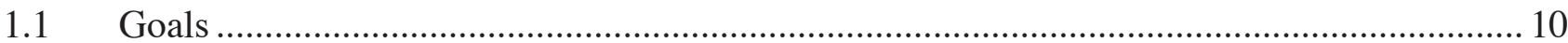

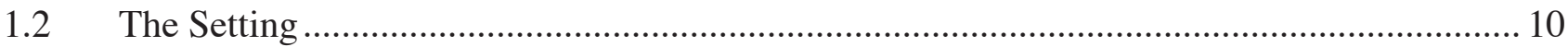

1.3 Key Events of the Cerro Grande Wildfire ................................................................... 12

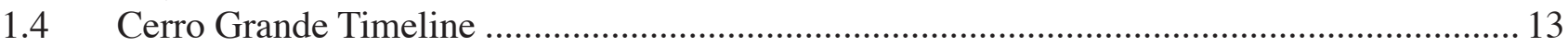

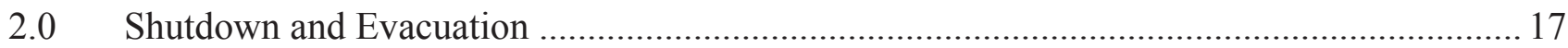

3.0 Geographic Information System (GIS) Needs for Emergency Management ....................... 17

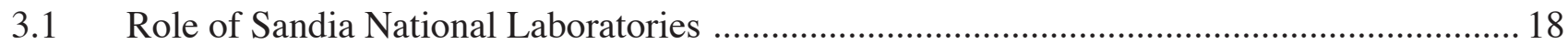

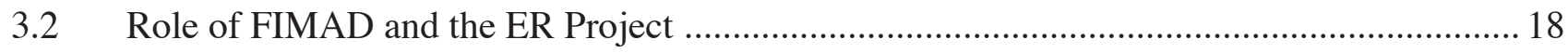

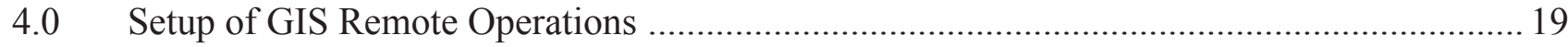

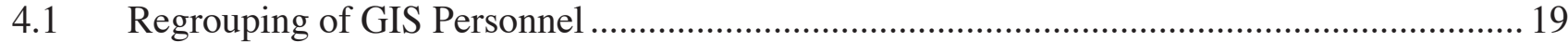

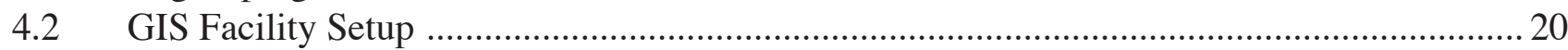

$4.3 \quad$ Logistics of GIS Remote Operations ......................................................................... 20

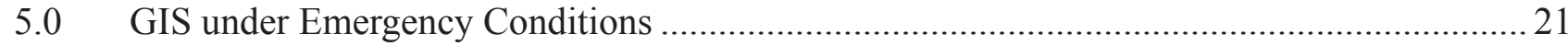

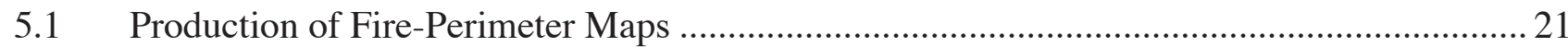

$5.2 \quad$ Updates of LANL Technical Area Maps ............................................................... 21

5.3 Staffing and Events at the LANL Emergency Operations Center (EOC) ..........................22

5.4 Modeling of Potential Flood and Erosion Areas .........................................................223

6.0 Return to Onsite LANL Operations ............................................................................ 23

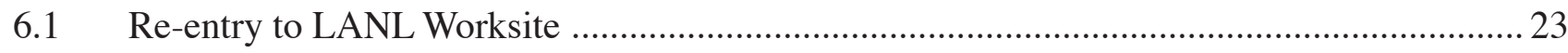

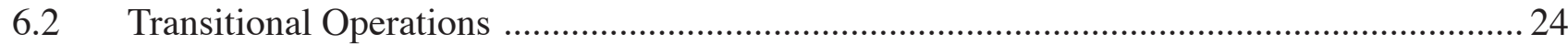

7.0 GIS Support of the Cerro Grande Rehabilitation Project (CGRP) ..................................2

7.1 Cerro Grande Rehabilitation Project GIS ................................................................ 27

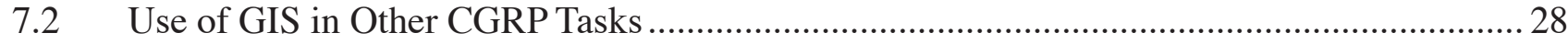

7.3 Special Achievement Award for Cerro Grande GIS Efforts .......................................... 30

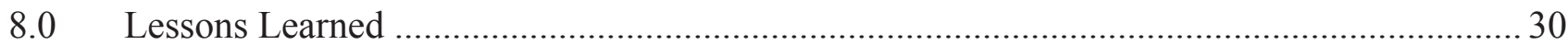

8.1 GIS provides an integrating framework for assessing natural and human hazards in a ............

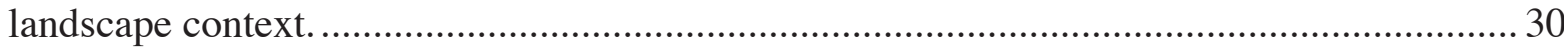

8.2 A strong GIS capability within LANL is needed for emergency response. ........................ 30

8.3 Coordinated emergency plans are needed for GIS operations. .......................................... 31

8.4 GIS and other employees need a method to report their whereabouts and to receive ............... authoritative information and instructions during an evacuation. ..................................... 32

8.5 GIS data should be complete, backed-up, and available during an emergency.................... 32

8.6 GIS procedures must be adaptable to the needs and circumstances of the emergency. ......... 33

8.7 The GIS community needs to more fully coordinate efforts. ........................................ 33

8.8 Institutional GIS resources should be more fully integrated into LANL operations............. 34

8.9 Key infrastructure information and geospatial data should reside on a LANL central computer repository - a data warehouse. 
9.0 The Future of GIS and Emergency Management ........................................................ 35

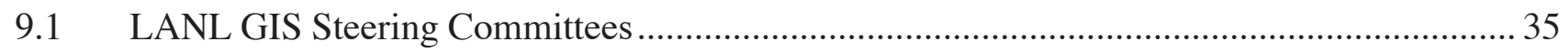

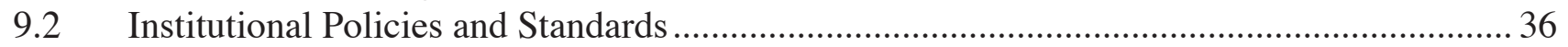

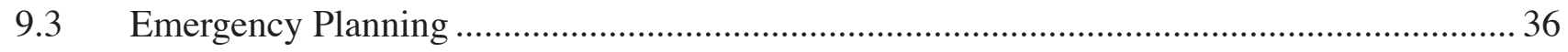

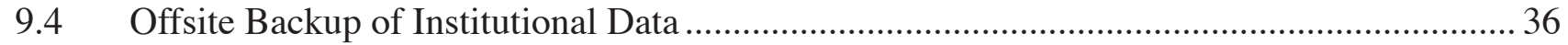

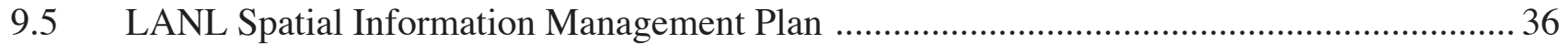

9.6 Coordination Within the DOE Complex and with Other Organizations .............................. 37

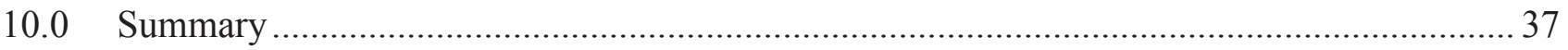

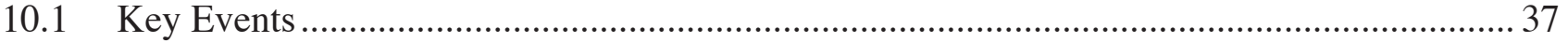

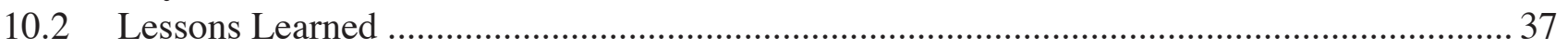

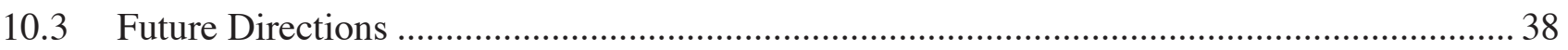

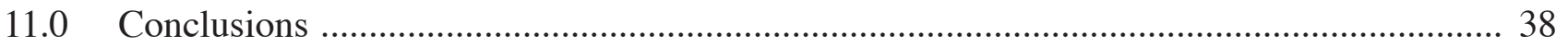

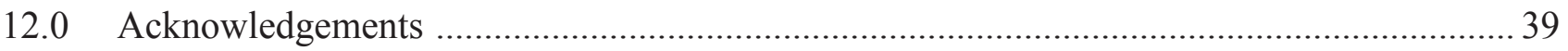

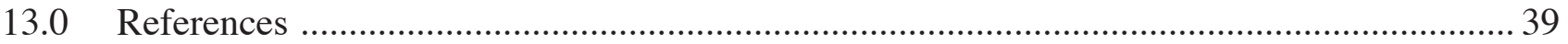

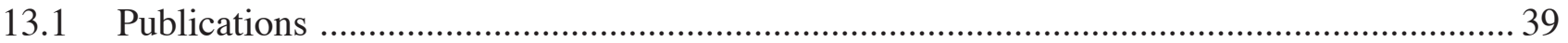

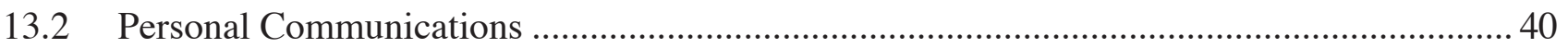

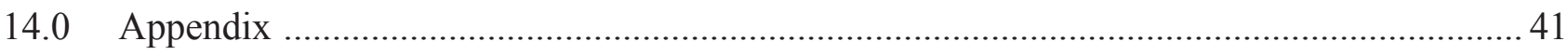

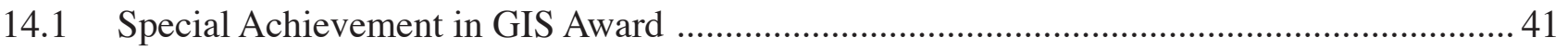




\section{List of Figures}

Figure 1. Location of Los Alamos National Laboratory $\quad$ V

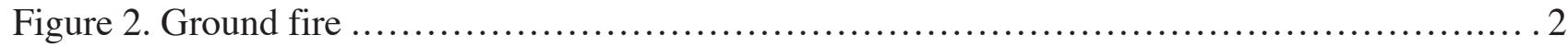

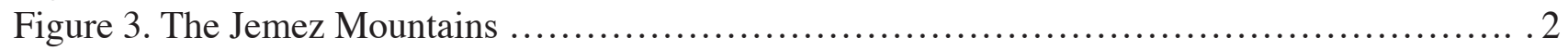

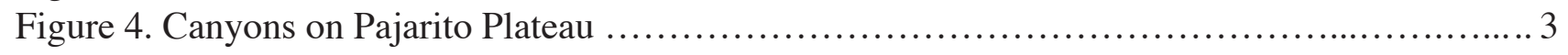

Figure 5. Topographic map of Los Alamos ................................................ 3

Figure 6. View west toward Los Alamos and the Jemez Mountains ............................ 4

Figure 7. Cerro Grande smoke plume on May 10, 2000 .................................. 4

Figure 8. Backfire set to protect Los Alamos from oncoming main fire ..........................5

Figure 9. Wildfire expanding into Los Alamos Canyon ........................................ 5

Figure 10. Fire approaching Los Alamos ............................................... 5

Figure 11. Fire entering Los Alamos .................................................. 6

Figure 12. Homes burning in Los Alamos ................................................6

Figure 13. LANL Emergency Operations Center ..........................................6 6

Figure 14. Smoldering ruins of a Los Alamos home ...................................... 6

Figure 15. Satellite image of Cerro Grande smoke plume reaching Kansas ....................... 7

Figure 16. Fire crews on mountain near Los Alamos .................................... 7

Figure 17. Smoke over burned LANL areas .......................................... 7

Figure 18. Burned Laboratory shop building ........................................... 7

Figure 19. Burned Los Alamos neighborhood .......................................... 8

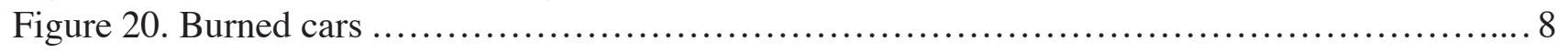

Figure 21. Laboratory director briefing the national news media ............................ 9

Figure 22. USFS worker preparing map of fire boundary ............................... 10

Figure 23. Forest Service Incident Management Team GIS facility ......................... 11

Figure 24. Thermal infrared satellite imagery of the Cerro Grande wildfire ...................... 12

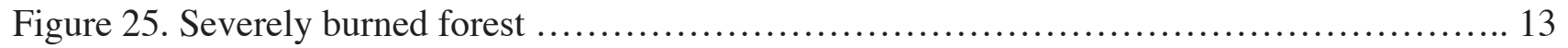

Figure 26. Watershed damage above Los Alamos Reservoir ............................... 14

Figure 27. Wreckage in a burned Lab building ......................................... 15

Figure 28. Stairs to nowhere; destroyed home in Los Alamos .............................. 15

Figure 29. Cerro Grande Fire Progression Map showing areas burned on successive days .......... 16

Figure 30. Flash flood debris flow on NM 501, June 28, $2000 \ldots \ldots \ldots \ldots \ldots \ldots \ldots \ldots \ldots \ldots \ldots \ldots \ldots \ldots$

Figure 31. Predicted effect of flood retention structure (FRS) downstream in Pajarito Canyon ...... 18

Figure 32. Corps of Engineers flood retention structure in Pajarito Canyon ....................... 18

Figure 33. CGRP GIS display at the LANL Bradbury Museum .............................. 19

Figure 34. CGRP GIS web pages ................................................... 19

Figure 35. Example of erosion model results .............................................. 20

Figure 36. ALS imagery of a canyon ................................................. 20

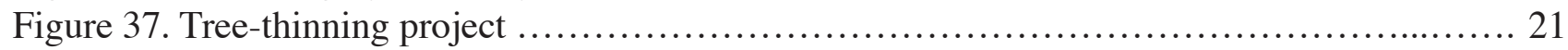

Figure 38. Dense forest fuels in the Jemez Mountains ..................................... 22

Figure 39. Enterprise GIS makes data and analysis capabilities available at an institutional scale .. 26

Figure 40. A complete geospatial data cycle ensures that data flow efficiently ................... 26

Figure 41. Map of Cerro Grande wildfire shown to young students ........................... 28

Figure 42 . Volunteers raking hydrophobic soil ............................................ 30

Figure 43. Wild irises blooming in burned area a year after the fire ........................... 30

Figure 44. Satellite multispectral imagery processed by GENIE technique ....................... 34 


\title{
Geographic Information System (GIS) Emergency Support for the May 2002 Cerro Grande Wildfire, Los Alamos, New Mexico, USA
}

by

\author{
C. Randall Mynard, Gordon N. Keating, and Paul M. Rich \\ Los Alamos National Laboratory \\ and
}

Denise R. Bleakly, Sandia National Laboratories

\begin{abstract}
In May 2000 the Cerro Grande wildfire swept through Los Alamos, New Mexico, burning approximately 17,400 ha (43,000 acres) and causing evacuation of Los Alamos National Laboratory (LANL) and the communities of Los Alamos and White Rock. An integral part of emergency response during the fire was the use of geographic information system (GIS) technology, which continues to be used in support of post-fire restoration and environmental monitoring.

During the fire Laboratory GIS staff and volunteers from other organizations worked to produce maps and provide support for emergency managers, including at an emergency GIS facility in Santa Fe. Subsequent to the fire, Laboratory GIS teams supported the multiagency Burned Area Emergency Rehabilitation (BAER) team to provide GIS data and maps for planning mitigation efforts. The GIS teams continue to help researchers, operations personnel, and managers deal with the tremendous changes caused by the fire. Much of the work is under the auspices of the Cerro Grande Rehabilitation Project (CGRP) to promote recovery from fire damage, improve information exchange, enhance emergency management, and conduct mitigation activities.

GIS efforts during the fire provided important lessons about institutional matters, working relationships, and emergency preparedness. These lessons include the importance of 1) an integrated framework for assessing natural and human hazards in a landscape context; 2) a strong GIS capability for emergency response; 3) coordinated emergency plans for GIS operations; 4) a method for employees to report their whereabouts and receive authoritative information during an evacuation; 5) GIS data that are complete, backed-up, and available during an emergency; 6) adaptation of GIS to the circumstances of the emergency; 7) better coordination in the GIS community; 8) better integration of GIS into LANL operations; and 9) a central data warehouse for data and metadata.

These lessons are important for planning future directions of GIS at LANL. Growing maturity of GIS is expected to lead to standardization and a better-integrated, more-coordinated approach to data sharing and emergency management at LANL, and within DOE, in accord with the federal government's increasing focus on electronic communication for its organizational and public interactions.
\end{abstract}




\subsection{INTRODUCTION}

The drama of the May 2000 Cerro Grande wildfire that was reported worldwide by the media did not fully capture the efforts of Laboratory employees and many others who performed valiantly under the stress, danger, and long hours imposed by the crisis. While most of the population of Los Alamos County evacuated and remained dispersed throughout northern New Mexico, small numbers of employees regrouped offsite and worked determinedly to provide data and maps desperately needed by emergency managers and others. Though the story of one particular group of these GIS professionals - the Facility for

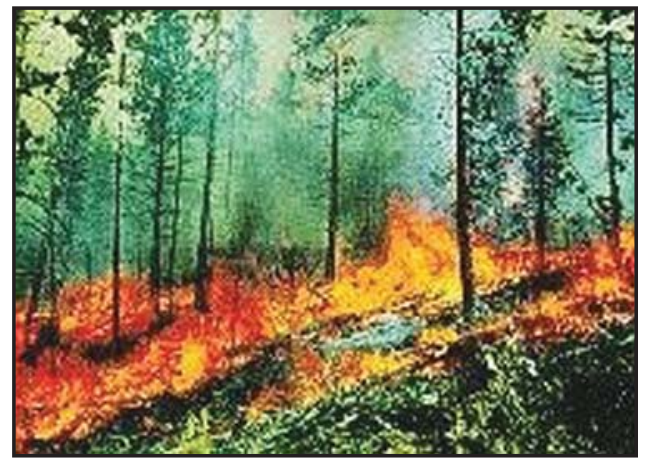

Fig. 2 - Ground fire (USFS) Information Management, Analysis and Display (FIMAD)/ GISLab - is emphasized in this report, other accounts of GIS being used during the emergency are also discussed. These include efforts by a number of organizations outside LANL, such as Johnson Controls Northern New Mexico, Sandia National Laboratories, and two multiagency teams. Credit goes to all the dedicated men and women who worked long hours, sometimes at personal risk, to provide GIS support for firefighting efforts and the post-fire recovery.

\subsection{Goals}

The goals for the report are three-fold:

- document key events and GIS activities during and subsequent to the Cerro Grande wildfire,

- analyze these events and GIS activities to draw important lessons, and

- provide a basis to guide the future role and use of GIS at the Laboratory.

\subsection{The Setting}

Los Alamos is a small city of 11,000 people in north-central New Mexico, located about $40 \mathrm{~km}$ (25 miles) northwest of Santa Fe at the foot of the 3,000+-m (10,000+-ft) peaks of the Jemez Mountains (Fig. 3). Home of the U.S. Department of Energy's (DOE's) world-famous Los Alamos National Laboratory, the town nestles amid a dense forest of pine, spruce, fir, and aspen draping the steep mountain slopes.

Los Alamos and the adjacent Laboratory sit on the eastward-dipping Pajarito Plateau. From the base of the mountains the plateau drops $500 \mathrm{~m}(1600 \mathrm{ft})$ to its abrupt end at steep cliffs along the Rio Grande [River]. These tall cliffs form a nearly impassible barrier along the east and

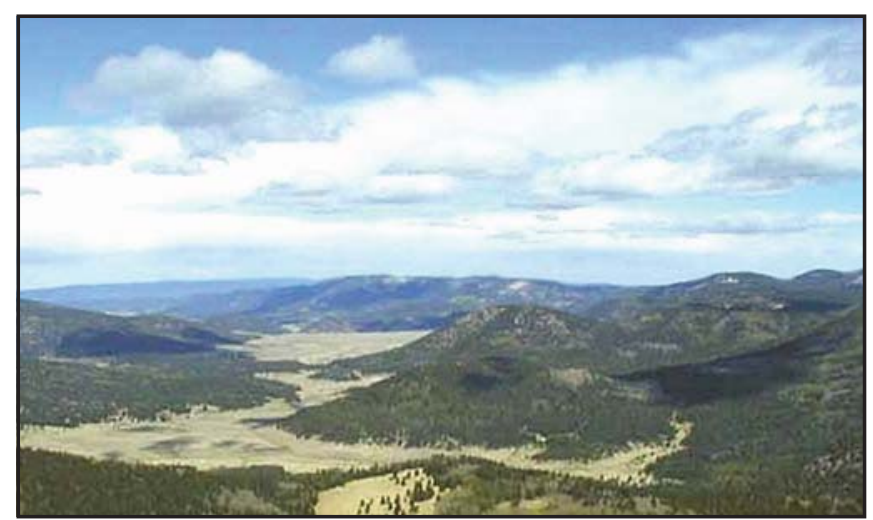

Fig. 3 - The Jemez Mountains (USFS). south margins of the Pajarito Plateau. Except for a narrow mountain road, only one main highway (Fig. 1) serves Los Alamos County due to the precipitous terrain, a factor in evacuations and emergency response.

A series of deep, vertical-walled canyons dissect the plateau's relatively flat surface and extend east to the Rio Grande (Fig. 4). Between these canyons are long, narrow, flat mesas on which sit most of the Laboratory 
facilities and the Los Alamos townsite. The irregular terrain (Fig. 6) impedes highway access, and the heavily forested canyons facilitate the rapid spread of fire, both of which are important factors with regard to combating forest fires that sometimes threaten the area (Fig. 2).

Sixteen km (10 miles) southeast of Los Alamos is the suburb of White Rock, population about 7,000 and

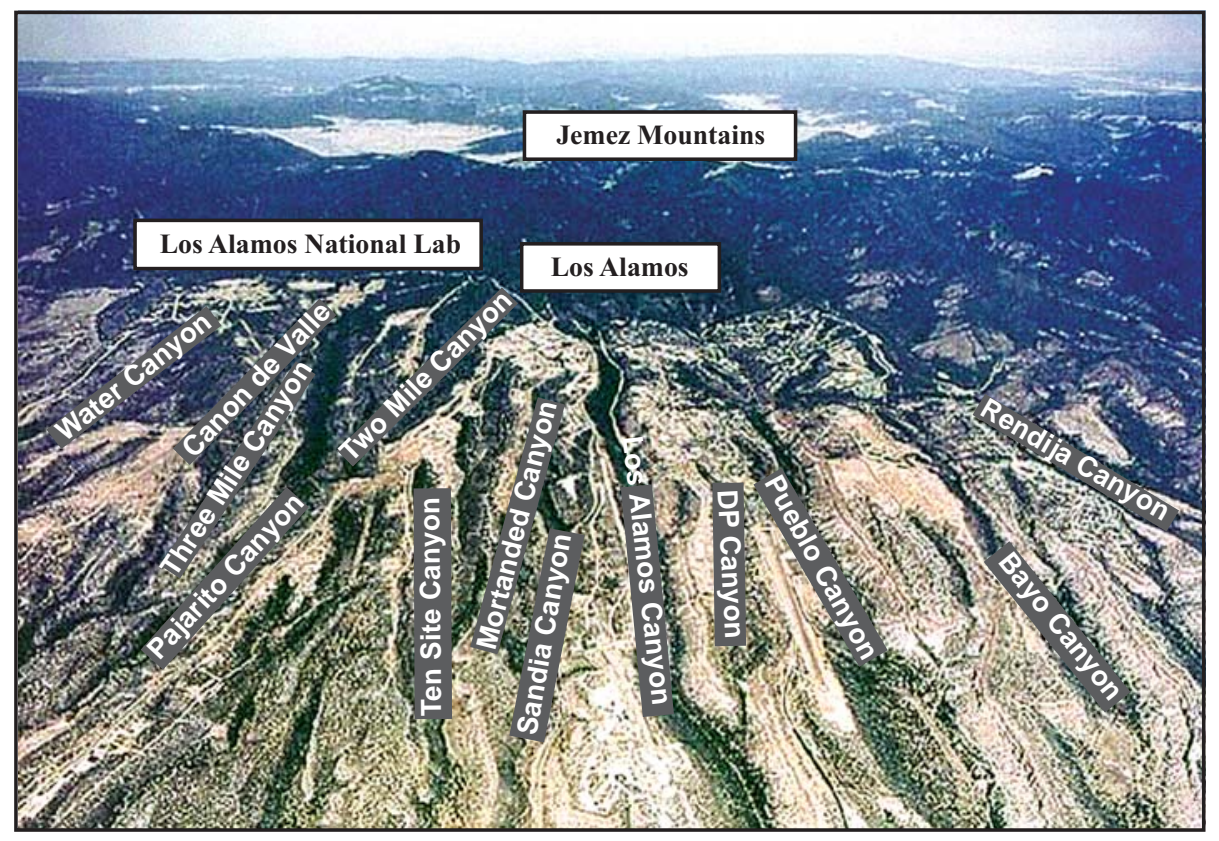

Fig. 4 - Canyon on Parajito Plateau, looking west (LANL).

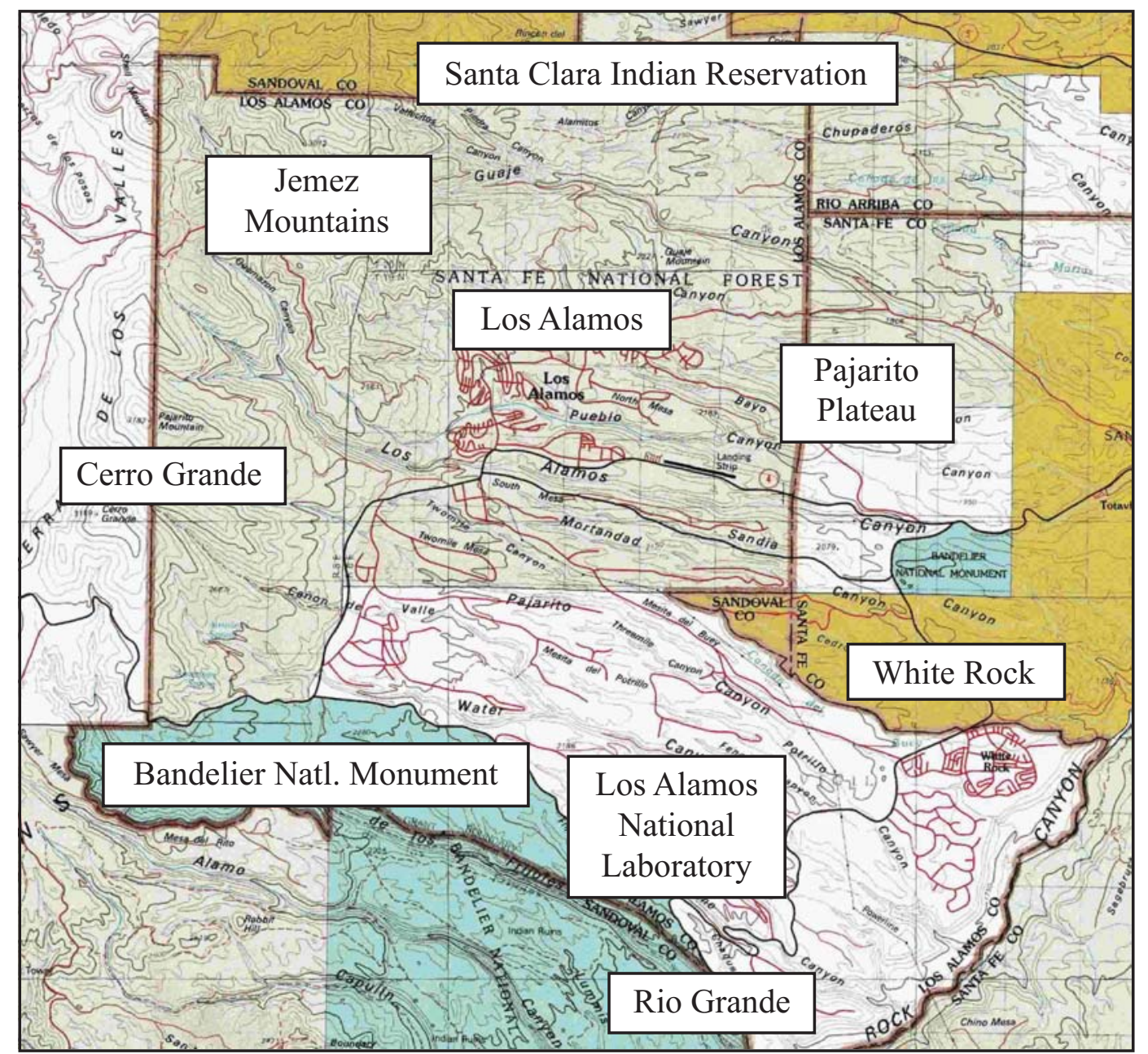

Fig. 5 - Topographic map of Los Alamos area (USGS 1978). Bandelier National Monument, shaded light blue, today includes Cerro Grande, the peak at left where the prescribed fire began. 
the only other community in Los Alamos County (Fig. 5). It is located at the edge of the $240-\mathrm{m}$ (800-ft) deep gorge of the Rio Grande, amid a pinyon pine-juniper woodland that carpets the plateau.

The Laboratory stretches between Los Alamos and White Rock, and consists of 11,596 ha $(28,654$ acres, or $44.8 \mathrm{sq} \mathrm{mi}$ ) of forested canyons and mesas (Buckley et al. 2002), among which are scattered isolated clusters of experimental

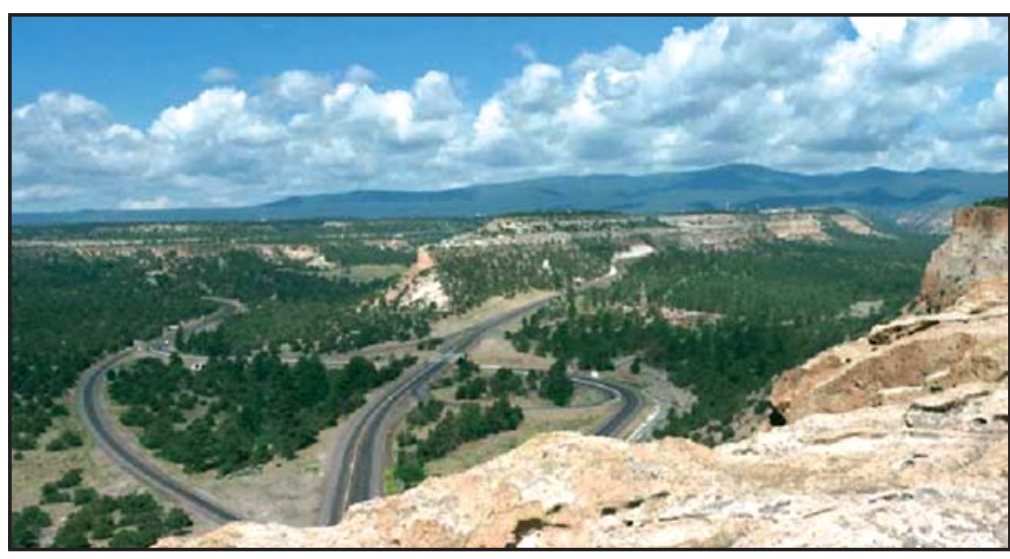

Fig. 6 - View west toward Los Alamos and the Jemez Mountains (LANL). facilities, testing areas and research laboratories. These are grouped geographically into numbered Technical Areas (TAs), outlined in green in Fig. 1.

Operated by the University of California for the DOE, the Laboratory is best known for its weapons research but is also considered one of the nation's world-class science and technology laboratories in many other fields, such as physics, climate change, computer science, biology, ecology, geology, etc.

Various factors played a role in the real and perceived risk during the Cerro Grande wildfire. About half of the Laboratory's land is devoted to testing that utilizes high explosives, which are stored in fireproof bunkers. The Laboratory's research, which dates to the famous Manhattan Project of World War II, has also long involved radioactive and hazardous materials. Because of this association with hazardous materials, certain locations are suspected of having potential contamination from past research activities. Called Potential Release Sites (PRSs), these locations are studied to determine their need for environmental remediation. PRSs could be a concern if fire or soil erosion threatens to disperse contaminants found to be present. Also, certain facilities that handle nuclear materials must obviously be protected from fire.

Especially since the nearby "Dome" fire in 1996, the Laboratory has made an effort to control fire risk by creating fuel breaks, corridors, or zones where potential fuels - fallen trees, forest litter, and overly dense vegetation - have been reduced (Webb and Carpenter 2001). Ironically, reduction of forest fuel is most efficiently done by the setting of prescribed fires (ScienceNow 2002). Such a fire began the catastrophic Cerro Grande wildfire.

\subsection{Key Events of the Cerro Grande Wildfire}

On May 4, 2000, National Park Service (NPS) personnel at nearby Bandelier National Monument ignited a prescribed fire on Cerro Grande, a mountain $6 \mathrm{~km}$ (4 mi) southwest of Los Alamos. Pre-fire conditions seemed appropriate for a controlled burn, but by the next day the fire had escaped its containment and began advancing eastward, pushed by strong winds. The blaze, then considered a wildfire, began spreading near

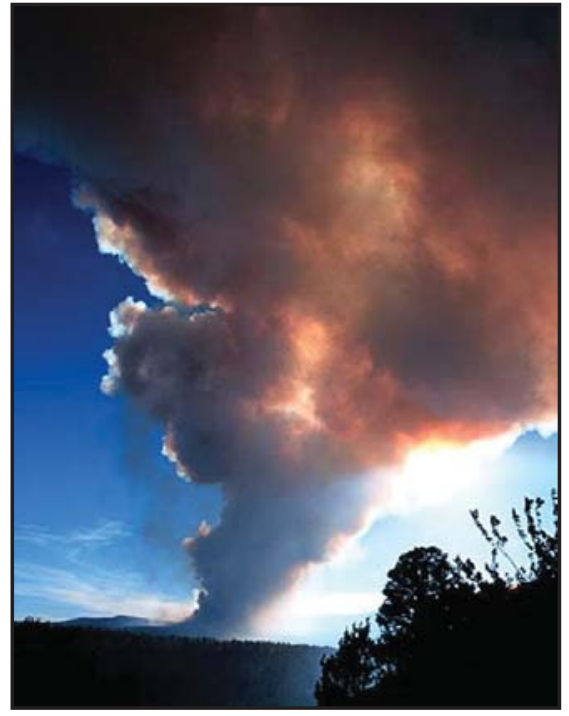

Fig. 7 - Cerro Grande smoke plume on May 10, 2000 (LANL). 
LANL (Fig. 7). The synopsis of events of the Cerro Grande wildfire described below is compiled from the following references: National Park Service et al. (2000), Grieggs (2001), and Webb and Carpenter (2001). Daily figures for acreage burned are approximate and are based on the area enclosed by fire perimeters.

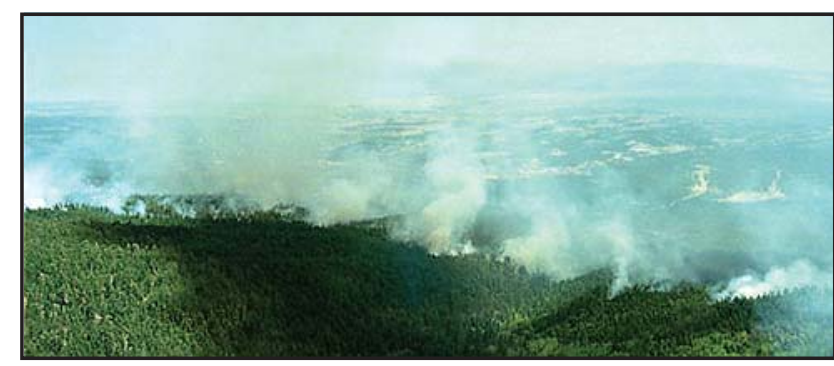

Fig. 8-Backfire set to protect Los Alamos from oncoming main fire ( $L A N L)$.

\subsection{Cerro Grande Timeline}

Thursday, May 4: At 7:30 p.m. the NPS began a 2200-ha (900-acre) prescribed fire on Cerro Grande. The fire behaved erratically due to relatively strong winds and threatened to escape the containment lines. NPS requested assistance from the U.S. Forest Service (USFS) overnight.

Friday, May 5: The fire grew beyond the containment line; NPS declared it an "escaped" fire. The NPS incident commander requested additional firefighting resources

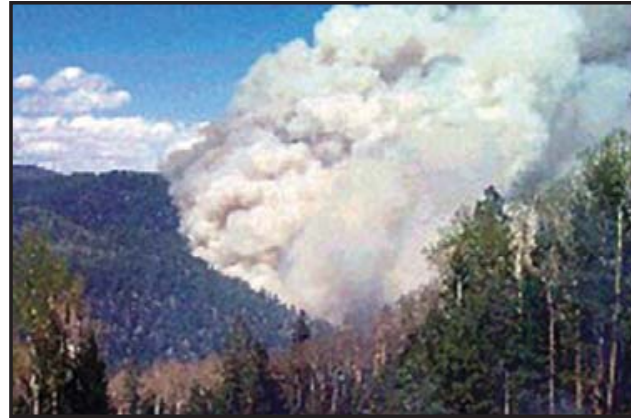

Fig. 9 - Wildfire expanding into Los Alamos Canyon (USFS). from USFS, including aircraft for fire-retardant slurry drops.

Saturday, May 6: Winds caused the fire to advance eastward toward Los Alamos. More firefighting teams arrived to cut fuel breaks, or fire lines, and to set backfires ahead of the flames (Fig. 8).

Sunday, May 7: Winds increased to $47 \mathrm{kph}$ (29 $\mathrm{mph}$ ), causing the fire to quickly expand. This "blowup" caused the NPS to declare Cerro Grande a wildfire. Aircraft began slurry drops on LANL property to stop spot fires caused by windblown embers. The growing threat to Los Alamos led to precautionary evacuation of western parts of Los Alamos. The Laboratory and Los Alamos County Emergency Operations Centers (EOCs) were activated, and TA-16, the Laboratory area closest to the fire, was evacuated in the afternoon. Laboratory management decided that night to close the LANL. The fire grew to 507 ha (1253 acres).

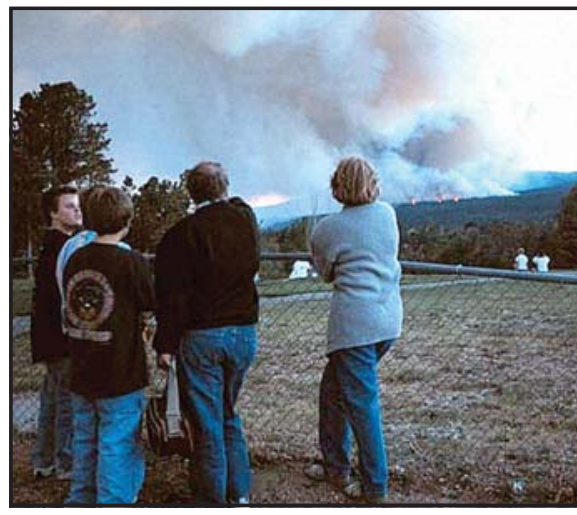

Fig. 10 - Fire approaching Los Alamos (LANL).

Monday, May 8: Only emergency workers and security personnel were allowed at the Laboratory, and Los Alamos Fire Department battled spot fires on LANL property. Los Alamos schools were also closed, while the fire slowly grew eastward toward the town. About 810 ha (2000 acres) had burned.

Tuesday, May 9: The fire doubled in size to 1740 ha (4300 acres). Ominously, the next day's forecast was for high winds. 


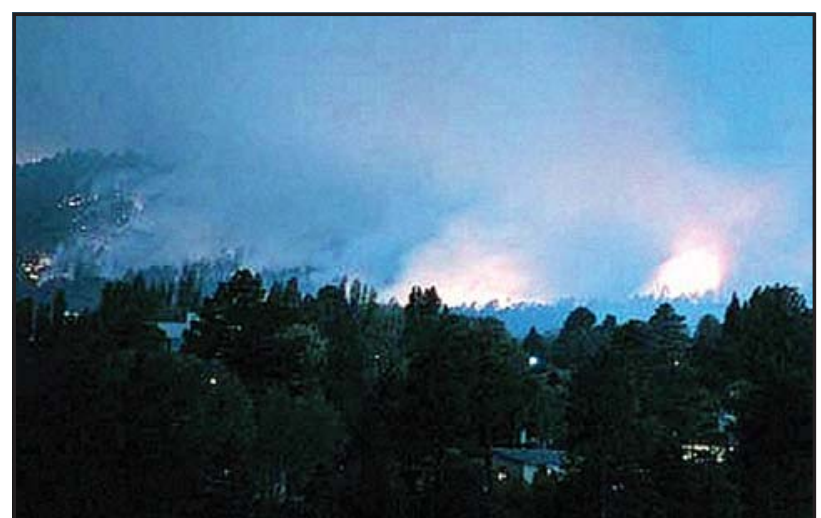

Fig. 11 - Fire entering Los Alamos (LANL).

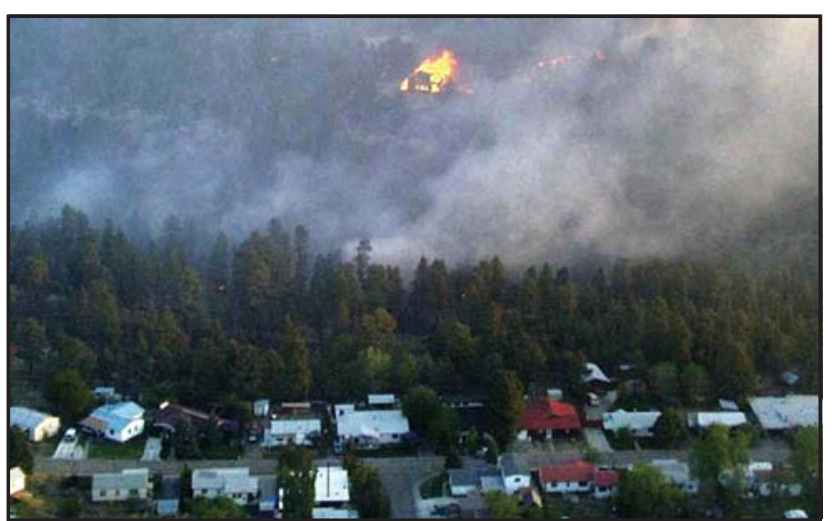

Fig. 12 - Homes burning in Los Alamos (LANL).

Wednesday, May 10: Winds increased dramatically and the fire "crowned" (reached treetops), allowing it to cross the last containment line and surge toward Los Alamos (Fig. 9). This prompted a total evacuation of the city at 1:00 p.m. In only 4 hours 11,000 residents safely departed, many to White Rock, where a Red Cross emergency shelter was set up for them. The fire swiftly crossed a deep canyon next to Los Alamos (Fig. 10). By early evening winds reached near-hurricane force, driving a roaring, 37-m (120-ft) high wall of flames into Los Alamos and incinerating homes near the forest (Figs. 11, 12). Glowing, winddriven embers rained $1.6 \mathrm{~km}$ ( $1 \mathrm{mi}$ ) or more ahead of the fire, causing spot fires to break out on Lab property beyond the fire break along the west side of the Laboratory.

The Cerro Grande wildfire thus split as a second front began spreading rapidly eastward across the Laboratory. Flames approached the Laboratory's EOC (Fig. 13) Wednesday evening, forcing staff to temporarily relocate to Laboratory offices in White Rock. The main fire was pushed rapidly northeastward, prompting voluntary evacuations in nearby Santa Clara Pueblo and western parts of Española by 10 p.m. President Clinton declared Los Alamos a federal disaster area. An additional 6150 ha $(15,200$ acres) burned in this single, disastrous day.

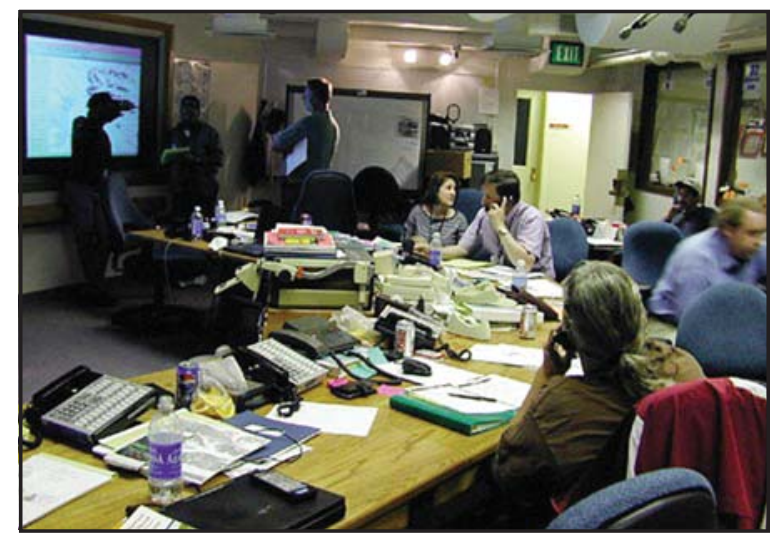

Fig. 13 - LANL Emergency Operations Center (FEMA).

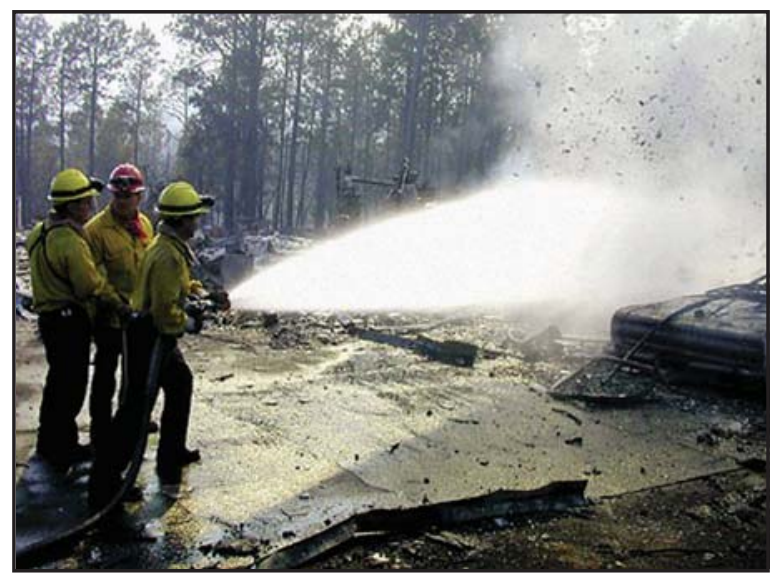

Fig. 14 - Smoldering ruins of a Los Alamos home (FEMA).

Thursday, May 11: Expansion of the fire toward several nuclear facilities caused White Rock to be evacuated at 1:07 a.m. and forced moving the temporary EOC to TA-49. As surprised, bleary-eyed residents slowly left in a bumper-to-bumper traffic jam, gusts to $97 \mathrm{kph}$ (60 mph) meanwhile rained burning embers onto Los Alamos, spreading fires in the western side of town. 
Firefighters fought desperately during the night to save the town and the Laboratory (Fig. 14). Flames reached the Laboratory EOC Thursday afternoon, forcing staff to again temporarily relocate.

Federal and state officials arrived and the Federal Emergency Management Agency (FEMA) began to arrange emergency aid. Moving $11.3 \mathrm{~km}$ (7 miles) during the day, flames finally stopped just 945 m (3100 feet) from White Rock's only remaining escape route (GISLab 2002). The towering, gray-brown smoke plume reached as far as Kansas, 400 km (250 miles) away, and covered nearby towns in dense smoke (Fig. 15). An additional

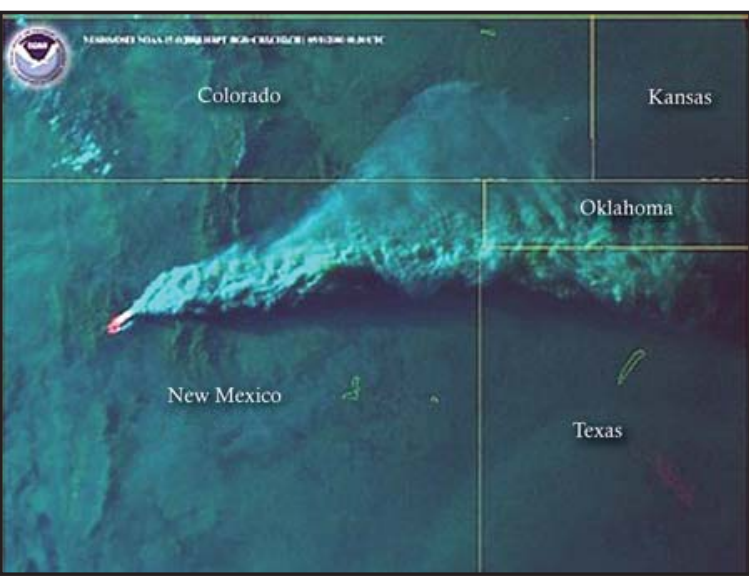

Fig. 15 - Satellite image of Cero Grande smoke plume reaching Kansas (NOAA). 5430 ha $(13,400$ acres $)$ burned.

May 12-13: Fire continued to spread in the mountains north of Los Alamos, entering Santa Clara Pueblo land and heading relentlessly toward the nearby city of Española. Heavily loaded aircraft and helicopters, flying close to mountainsides in gusts and dense smoke, repeatedly laid water and fire-retardant slurry on the fire. Their daring efforts had earlier helped keep flames from overwhelming Los Alamos. An offsite GIS facility, discussed in the next section, was set up in Santa Fe to help provide information about the possibility of radioactive contamination from PRSs in the smoke that lay over the area, an issue of public concern. By May 13, approximately 13,320 ha (32,900 acres) had burned.

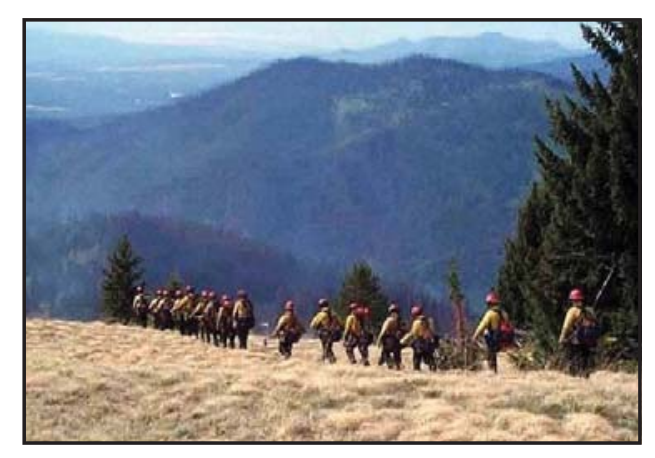

Fig. 16 - Fire crews on mountain near Los Alamos (LANL).

Sunday, May 14: The LANL Facility Recovery Center began damage assessment operations to determine which Laboratory facilities could be reopened to employees. Because the fire had not reached White Rock, those residents were allowed to return to their homes Sunday evening.

Monday, May 15: Residents were allowed into the unburned part of Los Alamos, but the destroyed western and northern neighborhoods remained closed due to hazardous home materials such as asbestos, ash from lead paint, and solvents. The multiagency BAER team* arrived to assess

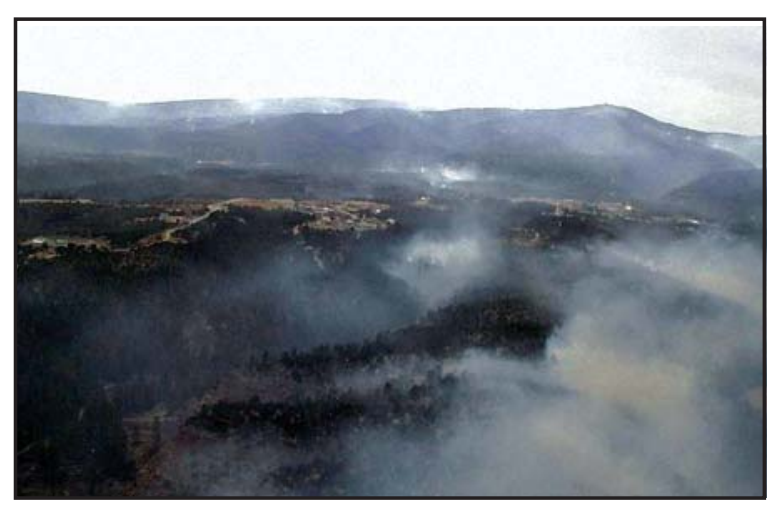

Fig. 17 - Smoke over burned LANL areas. Pajarito Rd. in distance (USFS). watershed damage and begin remediation efforts to

\footnotetext{
* Comprised of staff from the NPS, USFS, Bureau of Indian Affairs, DOE, LANL, County of Los Alamos, Pueblo of Santa Clara, and Pueblo of San Ildefonso.
} 
reduce the chance of flash flooding from the soon-expected summer monsoon rains.

Thursday, May 18: Containment of the Cerro Grande wildfire reached $80 \%$ despite windy conditions, high altitude, rugged terrain, and the long, irregular fire perimeter (Fig. 16). Of the more than 2400 firefighters from several western states who fought the fire, 700 personnel and their equipment were sent by 66 New Mexico civilian and military fire departments (Grieggs 2001). Even as the Cerro Grande firefighting effort continued, hundreds more firefighters arrived in New Mexico to fight

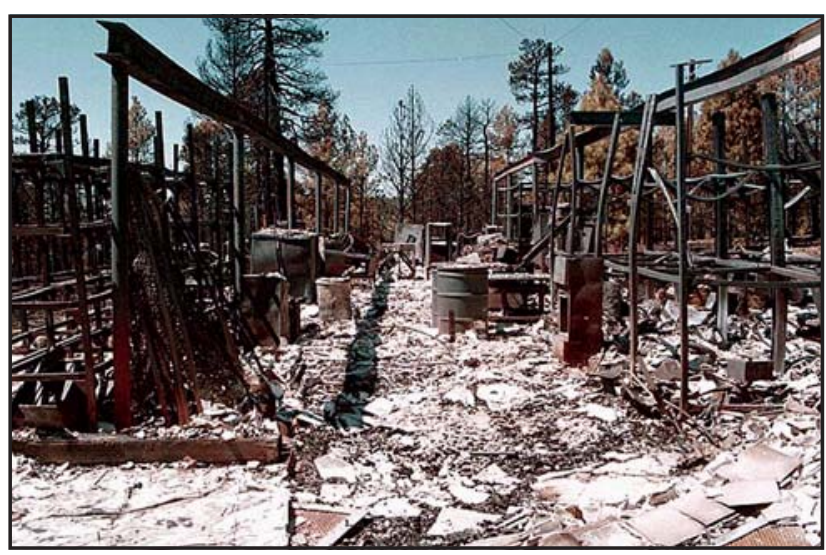

Fig. 18 - Burned Laboratory shop building (LANL). another large fire east of Santa Fe and a third fire in the state's southern mountains.

The Laboratory remained closed until Monday, May 22, a shutdown unprecedented in its 57-year history. No major structures were lost, but $28 \%$ of its land was burned (Fig. 17) and 112 small structures were destroyed or damaged (Fig. 18). Several small offices and their contents were lost, a serious blow to occupants' research. Laboratory operations were affected for months as damage was assessed, cleanup operations and hazard mitigation proceeded, and communication lines, poles, and utilities were gradually restored to outlying technical areas.

Two hundred thirty-nine structures were burned in Los Alamos (Fig. 19) and 429 families lost homes and most or all of their possessions (Fig. 20) (Grieggs 2001). Fortunately the fire took no human lives, though wildlife suffered some losses. Help from the federal government and from all over the world poured in, especially from New Mexico residents, businesses, and organizations. Their support was invaluable.

The fire was finally contained on June 6 , a month after it began, but it was not declared extinguished until September 25 (Grieggs 2001). A total of 17,400 ha (43,000 acres) were burned in the Jemez Mountains and Pajarito Plateau

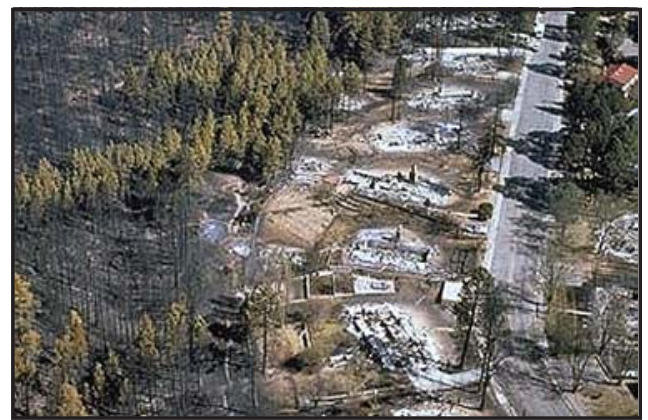

Fig. 19 - Burned Los Alamos neighborhood (FEMA).

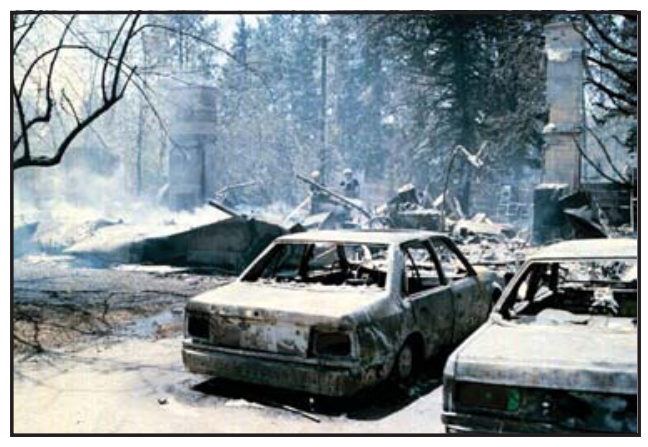

Fig. 20 - Burned cars (FEMA). (Buckley et al. 2002). This figure is based on the area actually burned rather than the early estimate of 19,400 ha (48,000 acres), which included unburned areas within the fire's perimeter. Quoted figures for the area that had burned each day similarly reflect varying estimates.

Within a year the stark, blackened hillsides began to be reclaimed by early-colonizing plants, though continuing drought has limited the rate of recovery. A major campaign was launched to re-establish ground cover and prevent flooding. Areas that experienced intensely hot crown fires will take longest to recover, in terms of the regrowth of the former forests. Stands of ponderosa 
pine will regrow within 50 years, a pace evident in areas burned by the nearby 1977 La Mesa fire, which 25 years later have 4-5-m (12-15-ft) tall ponderosa pines. However, the mixed conifer forest on higher slopes, which biologists expected to be dominated by fastrecovering aspen for many decades, may take up to 150-200 years to return (Foxx 2000).

\subsection{SHUTDOWN AND EVACUATION}

The decision to close the Laboratory on Sunday night, May 7, meant that most employees were not allowed to return Monday morning. Few, if any, offices had made preparations for possible closure the previous Friday when the fire was small, and by Monday it was too late to gather important records, data and equipment. Only with special permission could individuals return, so most stayed home and watched news coverage as the fire progressed.

One of the main GIS facilities at the Laboratory, and the focus of this paper, was FIMAD, now known as GISLab. FIMAD was the primary data repository and

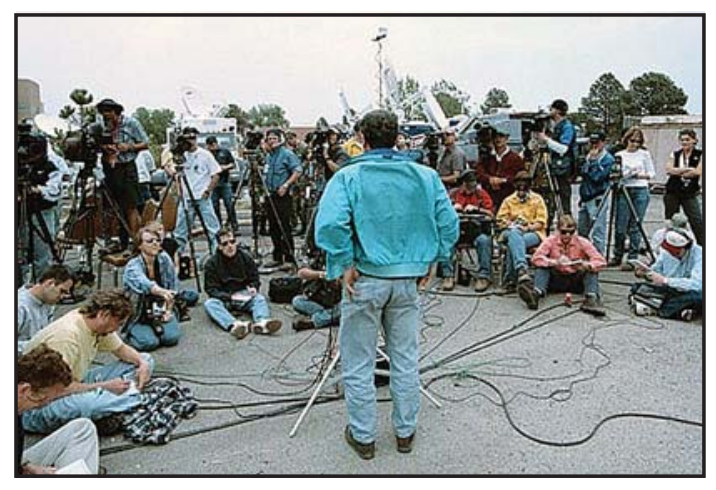

Fig. 21 - Laboratory director briefing the national news media (LANL). GIS resource for the Lab's large Environmental

Restoration (ER) Project, and its cartography lab produced over a thousand new maps each year. At that time FIMAD was part of the Earth and Environmental Sciences (EES) Division Geoanalysis Group (EES-5) at LANL. Due to the Laboratory's shutdown, FIMAD was closed but its computer servers continued to function unattended, because electrical power hadn't failed. These servers were connected to the Laboratory's intranet, which also remained online. That this link to the FIMAD servers remained was critical to later offsite GIS efforts.

A member of EES Division computer support staff, Carl Davenhall, who had earlier been assigned to work at home to create watershed maps for the ER Project, so happened to have a disc that contained half of the geospatial themes used by FIMAD, plus a copy of GIS software. When the evacuation occurred, his personal desktop computers, monitors, network hubs and cables became the basis for creating an offsite local area network. (Davenhall 2002). One of the FIMAD staff, Tom Garrison, had also been tasked to work at home on a different ER Project assignment. He had a disc containing the other half of FIMAD's geospatial themes. Together the two discs contained sufficient data for creating base maps of LANL (Bolivar 2002b).

Both of these employees lived outside the evacuation zone and were not displaced when the evacuation order was issued, unlike other FIMAD staff. This meant that 1) they could be located, and 2) their data and personal equipment resources were available. Evacuees, in contrast, carried only the personal belongings that they had time to gather and room to carry in their vehicles. Their primary concern was to get to safety and find lodging. Evacuees could not, in most cases, be considered a staffing resource until days later, even if their location was 
known. GIS efforts during the emergency therefore depended heavily on staff who did not live in the affected area.

\subsection{GEOGRAPHIC INFORMATION SYSTEM (GIS) NEEDS FOR EMERGENCY MANAGEMENT}

The public and local governments voiced concerns about whether chemical or radiological contaminants might be present in smoke, or later be washed from denuded soils. Laboratory emergency managers, also, needed as much information as possible about the fire and its effects (Fig. 21). This included where the fire was actively burning and where it had burned, what facilities were at risk, what structures had been burned, what infrastructure and utility damage had been sustained, where new fire roads were located, and which PRSs were burned or might be in the fire's path. Analytical data about possible contaminants in the affected PRSs were also needed.

Such diverse data were formatted in various ways, required different software, and used different operating systems. Access to datasets required user permissions and passwords, meaning that only certain employees could

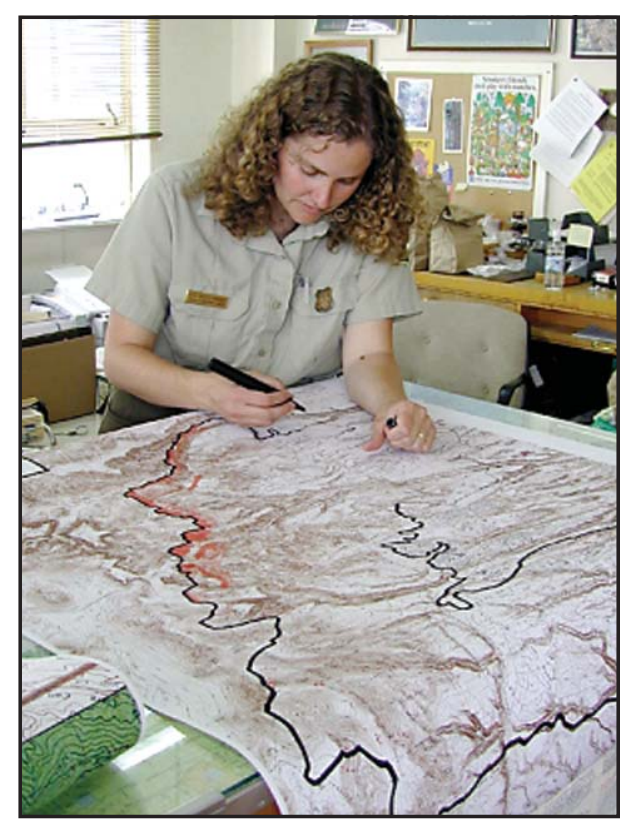

Fig. 22 - USFS worker preparing map of fire boundary (FEMA).

obtain the data. In addition, the data were on numerous servers, most of which, including the FIMAD servers, were inaccessible due to the evacuation of key personnel and the continuing danger from fire (Coffman et al. 2000b).

The resulting need for GIS support was evident, but a challenge was how to provide it from an offsite location and how to access the necessary data. An offsite GIS capability had to be quickly created. The first problem was to arrange for staffing, because we had not located most staff who had evacuated. In the interim, GIS facilities at Sandia National Laboratories began supporting the emergency activities.

\subsection{Role of Sandia National Laboratories}

The USFS had a GIS capability for preparing daily operations maps for fire crews and for briefing the news media (Fig. 22), but specialized maps of LANL facilities were also needed. Sandia became involved with the Cerro Grande wildfire response in order to support the DOE Albuquerque Operations Office, which was responsible for the two national laboratories. The Environmental GIS (EGIS) office at Sandia created fire maps for the DOE EOC in Albuquerque, which used these maps to make essential decisions about LANL assets that might be at risk. EGIS served primarily as a data gathering/distribution node rather than as a "production shop," and provided fire-perimeter data needed by DOE field teams who were monitoring for radiation and chemical releases in and around LANL.

Denise Bleakly of EGIS called members of the New Mexico Geographic Information Council (NMGIC) for assistance on May 13 and quickly received regional GIS datasets from them at no cost. 
Contributors included Liz Peck and Bob Bewly of the Bureau of Land Management, Candice Bogart of the USFS, and Laura Gleasner and Mike Inglis of the University of New Mexico Earth Data Analysis Center (EDAC). These data enabled Sandia to prepare initial fire maps.

\subsection{Role of FIMAD and the ER Project}

At 1:30 a.m. on the Friday morning after the evacuation from White Rock (May 12), Julie Canepa, project director of the ER Project, received a phone call from the LANL EOC. Denny Erickson, director of the Environment, Safety and Health (ESH) Division, and Joe Vozella of DOE asked that ER set up a team in Santa Fe and begin assessing the impact of the fire on the PRSs. ER requested use of the Laboratory's Waste Isolation Pilot Project (WIPP) reading room in Santa Fe as a command center and put into action the FIMAD GIS team.

ER Project personnel who lived outside Los Alamos County were immediately called and asked to begin working Friday at the ER

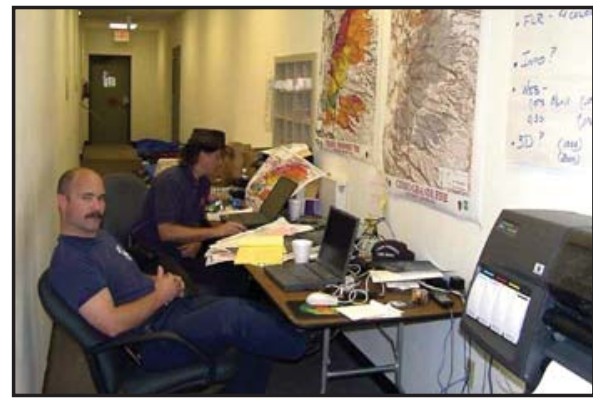

Fig. 23 - Forest Service Incident Management Team GIS facility (USFS).

Project center, and a request was made in the Santa Fe newspaper for other ER Project staff and contractors to meet there Saturday morning. The telephone system in Los Alamos still worked, so messages were left on home-phone answering machines for those who checked their machines remotely. By these methods the necessary personnel were contacted.

It was clear that ER Project data on the FIMAD system needed to be accessed, so the ER Project information manager, Steve Bolivar, contacted Carl Davenhall to make appropriate arrangements and to set up an offsite GIS facility. For this purpose the ER Project made use of an existing subcontract with the Loft4 Digital Media Studio in Santa Fe. To support the FIMAD efforts during the emergency a "safe" place was needed to store sensitive project data, and Sandia National Laboratories offered this service. The ER Project director authorized the release to Sandia of necessary ER Project data that resided at FIMAD (Canepa 2002).

\subsection{SETUP OF GIS REMOTE OPERATIONS}

\subsection{Regrouping of GIS Personnel}

Loss of contact among residents is inevitable when an evacuation occurs, but the double evacuation in Los Alamos County created a chaotic change of plans for evacuees. Los Alamos residents who chose to stay with friends in White Rock were abruptly evacuated a second time in the middle of the night, with little time to inform anyone of their change of location. Evacuees often had little or no information about the whereabouts of coworkers and neighbors. White Rock residents quickly loaded their vehicles and simply vanished into the smoky, orange-lit night.

Many evacuees stayed with relatives or friends in the region, in Red Cross shelters, in hotels in the region, in recreational vehicles parked at local businesses, or even with strangers who graciously offered their homes. Finding evacuated coworkers was extremely difficult, though electronic bulletin boards, sign-up lists at shelters and churches, and online databases were of help to those who knew about and could access these services. GIS staff of Project Management Division's Project Planning Group (PM-1), for example, happened to find each other a week later at a Red Cross facility/postal center (Stockum 2002). 
Serendipity played a role in the regrouping of GIS staff as it did in locating equipment and GIS software. Steve Bolivar of the ER Project first evacuated and, upon learning of ER's need for project data, went to the home of Carl Davenhall to discuss how to meet the mapping and data needs of emergency managers. Contact was made with Tom Garrison of the FIMAD staff, who also lived outside the evacuated area, and with Rick de Saussure of Loft4 (Davenhall 2002).

The combination of these four people allowed the necessary linkage of mission concept, basic equipment, GIS expertise, data for maps, networking experience, and office space at de Saussure's Loft4 graphics studio in Santa Fe. In 48 hours the group established an improvised GIS facility at Loft4, utilizing the additional staff and equipment there (Bolivar 2002a).

\subsection{GIS Facility Setup}

The GIS operation in Santa Fe initially involved a single personal computer and one copy of GIS software. To augment this setup Loft4's computers, which used a different operating system, were pressed into service. Hardware and software compatibility issues first had to be resolved, then a local network with an Internet node was created to provide e-mail capability and to allow the staff to reach the LANL network. The EES computer team leader, Lynn McDonald, was contacted to make arrangements for retrieving PRS data from the FIMAD server in order to produce needed maps (Davenhall 2002).

\subsection{Logistics of GIS Remote Operations}

Loft4 had no capability for printing full-size maps, so at first the maps were printed on a largeformat plotter at a local commercial copy center. Because maps were being generated 24 hours a day, the only way to retain use of the plotter was to keep it in continuous operation. The staff therefore repeatedly sent maps, even if they had already been printed, to maintain their place in the queue. This creative but rather inefficient procedure was eventually resolved, doubtless to the relief of the copy center, by ordering a plotter from Albuquerque. The vendor was convinced to deliver the

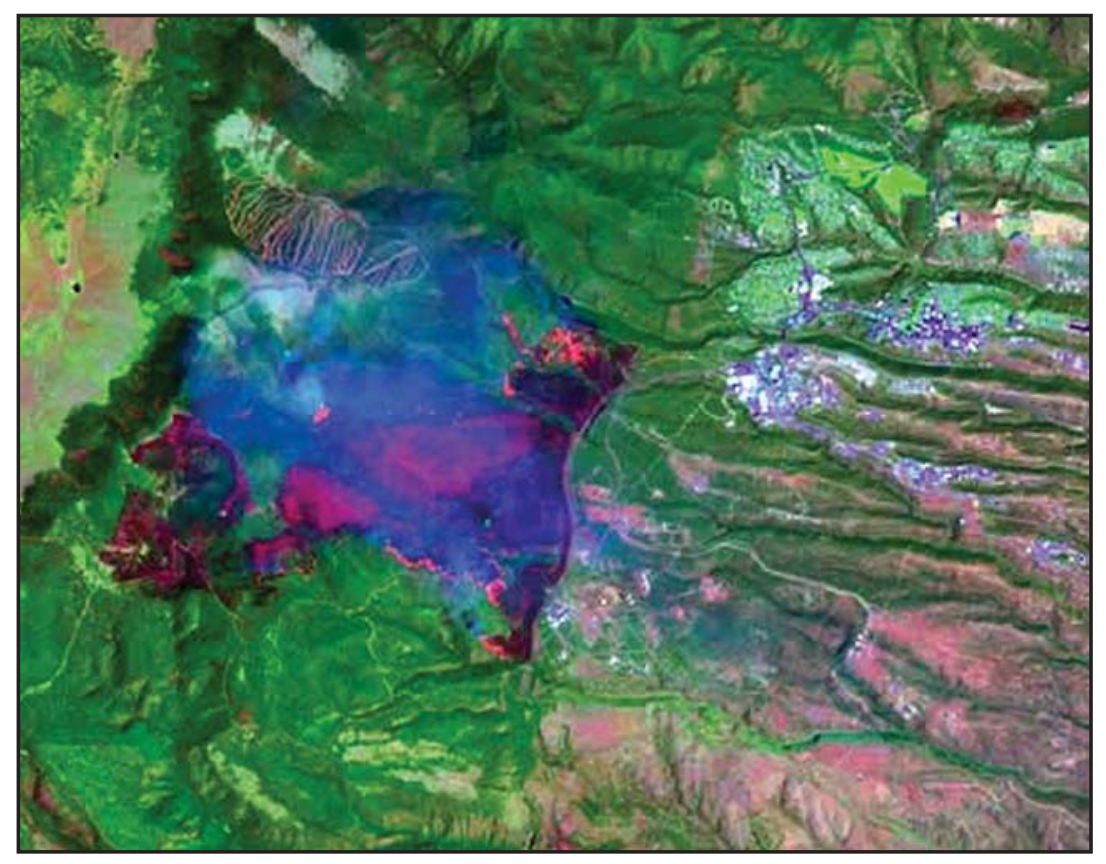

Fig. 24 - Thermal infared satellite imagery of the Cerro Grande wildfire. Taken by LANDSAT 7 May 9, 2000. North is at top. Areas of active burning are scarlet. Burned areas are magenta. Pink areas are lightly vegetated, such as the linerar ski runs at upper left. Los Alamos is at upper right. Bright green areas are a golf course and yards. Streets are purple. Smoke is blue. Note sharp edge of burned area at center, along a highway that served as a fuel break protecting LANL, at right $(\mathbf{N} \boldsymbol{A} \boldsymbol{S} \boldsymbol{A})$. 
expensive piece of equipment to Loft4 rather than to LANL because of the emergency, but the plotter was delivered overnight. It was assembled and put online in only 3 hours (Davenhall 2002).

The emergency situation demanded unique solutions to many normally lengthy administrative procedures. Inventiveness, patience, and flexibility were crucial, because no one was at LANL to handle business as usual. Decisiveness can often work wonders in such a trying situation, as long as the paperwork eventually catches up. All purchases were made using a Laboratory credit card because no other funding methods were available (Bolivar 2002b).

\subsection{GIS UNDER EMERGENCY CONDITIONS}

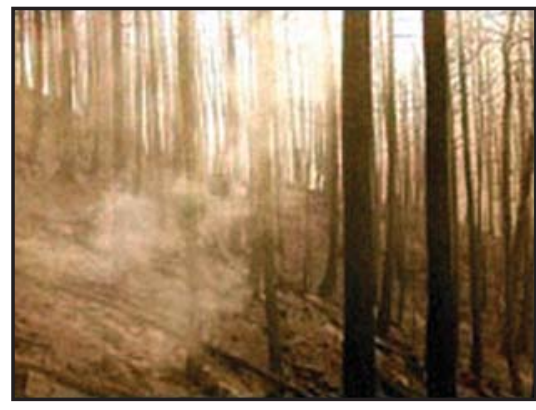

Fig. 25 - Severely burned forest (FEMA).

\subsection{Production of Fire-Perimeter Maps}

The ever-changing location and rapid progression of the Cerro Grande wildfire as it was pushed by strong winds made managing the emergency response efforts difficult. Constantly updated maps were critical for Laboratory managers and firefighters to be able to decide what response efforts to make and how to deploy the hundreds of personnel on the fire lines (Fig. 23). The fire's division into two fronts when it jumped the main firebreak along the Laboratory's west border increased the complexity of the response and posed a new and serious threat to the Laboratory.

Location data about the rapidly moving fire came from infrared imagery taken during nightly overflights conducted by the Bureau of Land Management (BLM). After midnight BLM staff would digitize this imagery, which showed areas of active burning (Fig. 24), to create polygon or line files. These were relayed each morning to the Sandia EGIS where they were converted to spatially referenced overlays of fire perimeters and hotspots overlaid onto base maps of the Los Alamos area that had been provided by the USFS.

Sandia staff then electronically transferred the map files to the FIMAD server at Los Alamos, or in some cases transferred the files directly to Loft 4 . The files were then downloaded from the FIMAD server to Loft4 and used to create hundreds of maps that showed the expanding burned areas in relationship to potentially contaminated areas (the PRSs). The updated maps were printed and taken to the LANL EOC by staff at the ER Project command center in Santa Fe, which also relayed map requests from the EOC to the staff at Loft4 (Bolivar 2002b).

GIS efforts at Loft4 continued 24-hours-a-day for 10 days to produce the fire maps. Laboratory and Loft4 personnel, divided into shifts, quickly developed team roles and responsibilities and were very effective during the demanding hours of around-the-clock operations. Data management, data processing, cartography, map printing, arrangements for meals and refreshments, transportation to pick up consumables, ferrying maps to LANL, and coordination with Sandia and the LANL EOC all ran efficiently once procedures were established and adjusted to evolving circumstances. Teamwork and shift coordination were excellent under the intense conditions, but the stress was sometimes evident as the effort continued day after day. Stress management is critical for such sustained effort.

\subsection{Updates of LANL Technical Area Maps}

A number of subcontractor personnel were actively engaged in GIS work during the emergency. Harold Salazar, from the Utilities Mapping office of Johnson Controls Northern New Mexico 
(JCNNM-UMAP), led a crew that used global positioning system (GPS) units to map new fire roads as they were being created. They followed bulldozers that were cutting roads and firebreaks even as the fire raged nearby. Meanwhile, Chris Samora of JCNNM-UMAP provided GIS support from the main office at TA-3. The field mapping, done at night and in dense smoke, was not without personal risk (Gonzales 2002 and Salazar 2002).

\subsection{Staffing and Events at the LANL Emergency Operations Center (EOC)}

Two members of the ESH Division, John Huchton of the Ecology group (ESH-20, now RRES-ECO) and Diana Webb of the ESH Division Office, reported to the LANL EOC when it was activated. They provided biological and archeological data, maps, and advice to emergency managers during the fire, and coordinated with other ESH-20 staff assigned to guide fire crews and bulldozers around sensitive locations. Due to computer network problems during the fire, online download of such data from ESH-20 servers was not always reliable, so the staff manually copied data from the server and hand-carried it to the EOC (Koch 2002).

The evening of May 10 the LANL EOC staff, including the ESH representatives, was suddenly evacuated when a hundred-foothigh wall of flames rapidly approached the heavily wooded canyon adjacent to the facility. Amid the roar, smoke, and glare of the oncoming flames, and with the fire only a hundred yards from reaching the opposite canyon rim, employees ran to their cars and

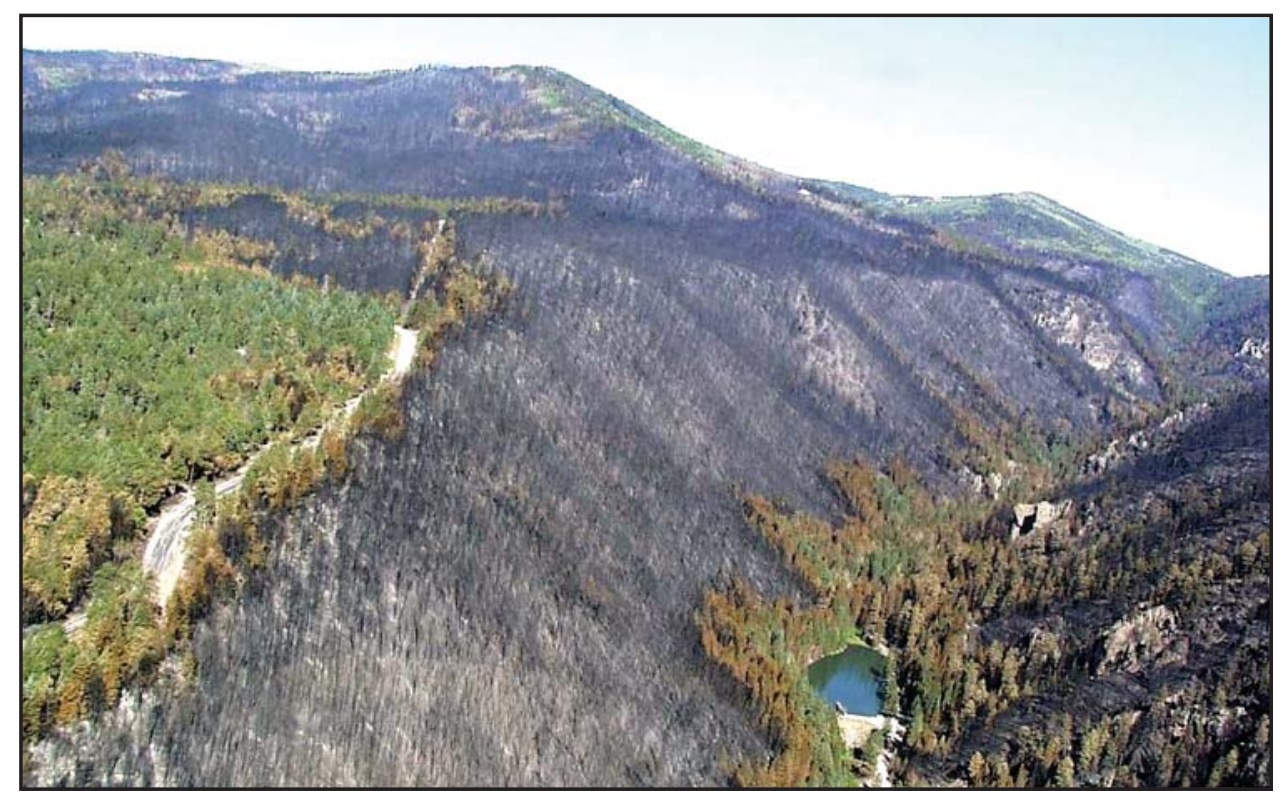

Fig. 26 - Watershed damage above Los Alamos Reservoir (ESH Division, LANL, 2000). raced past the fire to the LANL Training Center in White Rock (Huchton 2002). The fire spilled into the canyon and turned eastward toward several nuclear facilities and the community of White Rock.

Thirteen of the EOC staff, desiring to maintain continuity of emergency management, bravely chose to remain in the basement structure as the flames rose from the canyon and burned the trees just outside (Howard 2002). The finger of fire spread across Pajarito Road into the wooded canyon to the north. Then it, too, turned eastward toward the nuclear facilities, which were threatened with being sandwiched between the fires in the two adjacent canyons. The threat to the radioactive waste storage facility at TA-54 led to the precautionary order to evacuate White Rock (Grieggs 2001). Firefighters successfully kept the fires from reaching any of the nuclear facilities, but several other research sites along Pajarito Road were damaged. The forest suffered serious damage (Figs. 25, 44). 
Upon evacuation of White Rock, the displaced EOC personnel there were ordered to activate the secondary EOC, located at TA-49 behind the fire. They worked there around the clock for 48 hr until it was safe to return to the primary EOC, which was twice again nearly overrun by fire (Huchton 2002, GISLab 2002). The Laboratory's Emergency Management and Response Group (S-8) staff in the EOC maintained equipment and communication, acquired meteorological data from locations around the Laboratory, and posted hardcopy and electronic maps from various sources, especially the fire progression maps overlaid with PRS contamination data. These maps, created by FIMAD staff in Santa Fe, were used to plan Laboratory response to the ever-changing fire threat, mark locations of new fire roads, and denote structures at risk, damaged, or destroyed (Howard 2002).

\subsection{Modeling of Potential Flood and Erosion Areas}

The Environmental Science Group, EES-15 (now EES-10), utilized GIS to create input layers for simulating hydrologic conditions of the Pajarito Plateau with a range of runoff and

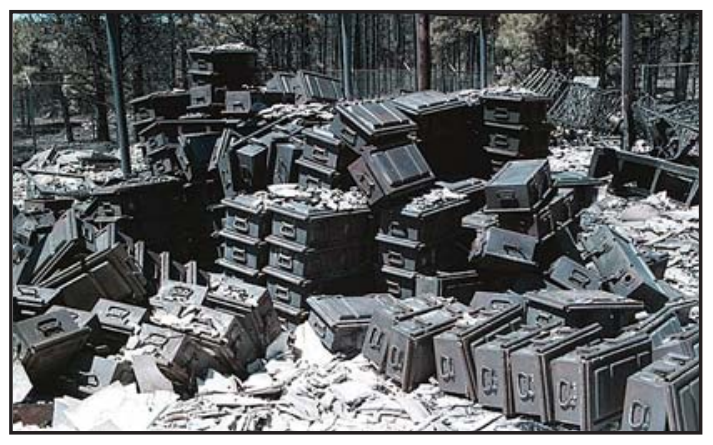

Fig. 27 - Wreckage in a burned Lab building (LANL). erosion models, including SPLASH and KINEROS. Before the fire, these models were being used to examine impacts of drought and landscape disturbance at material disposal areas (a type of PRS) for vegetation, runoff, and erosion processes. GIS maps of soil, vegetation, and other terrain attributes were required as input to the models, and GIS tools were used for visualization of model output. The models were used to help identify areas at LANL that were vulnerable to transport of soil contaminants.

The EES-15 staff realized the threat of post-fire runoff and an immediate need to model hydrological changes that might result from the fire (Fig. 26), which required use of the software and data on computers still at work. A fire crew escorted members of EES-15 to collect the necessary computers. Upon arrival at TA-51 they

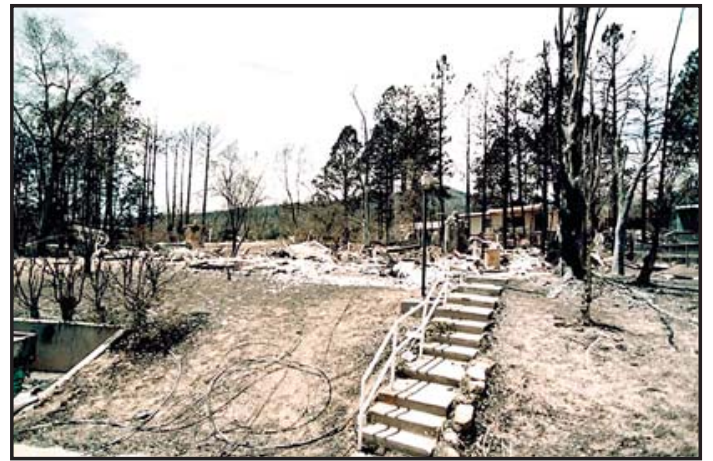

Fig. 28 - Stairs to nowhere; destroyed home in Los Alamos (LANL). discovered several spot fires near the buildings, which they extinguished to protect the buildings. They returned to Santa Fe and set up a temporary office at the ER Project command center to do runoff simulations but due to the congested conditions, later moved to the home of one of the group. SPLASH runs were performed there while the Cerro Grande wildfire was still burning strongly and were used to identify areas that posed threats to humans, infrastructure, and the environment should a large rain event occur. (Beeson 2002 and Wilson 2002).

\subsection{RETURN TO ONSITE LANL OPERATIONS}

Laboratory GIS personnel returned to work as soon as their offices were cleared for reoccupancy. The main technical area, TA-3, had not been burned so was quickly operational, but outlying areas were closed for a considerable period of time while utility poles and lines were replaced, roads and structures were cleared of debris, and buildings and equipment were repaired and cleaned (Fig. 27). 


\subsection{Re-entry to LANL Worksite}

Fortunately none of the LANL GIS facilities were damaged or destroyed in the fire. Many Laboratory buildings escaped due to timely efforts of firefighters. For example, the fire stopped

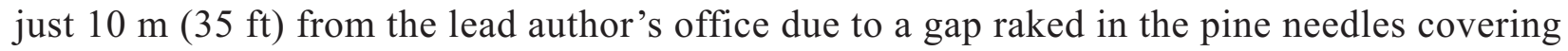
the ground. FIMAD, at TA-3 near a section of forest that escaped the fire, was undamaged.

The GIS facility used by PM-1, located at a leased former school in a heavily burned area of town, sat undamaged amidst charred grass and blackened trees. Stark, ash-covered foundations of destroyed homes (Fig. 28) and blackened trees extended around the building for blocks. EES-15's offices at TA-51 survived unscathed, due in part to the staff's impromptu firefighting

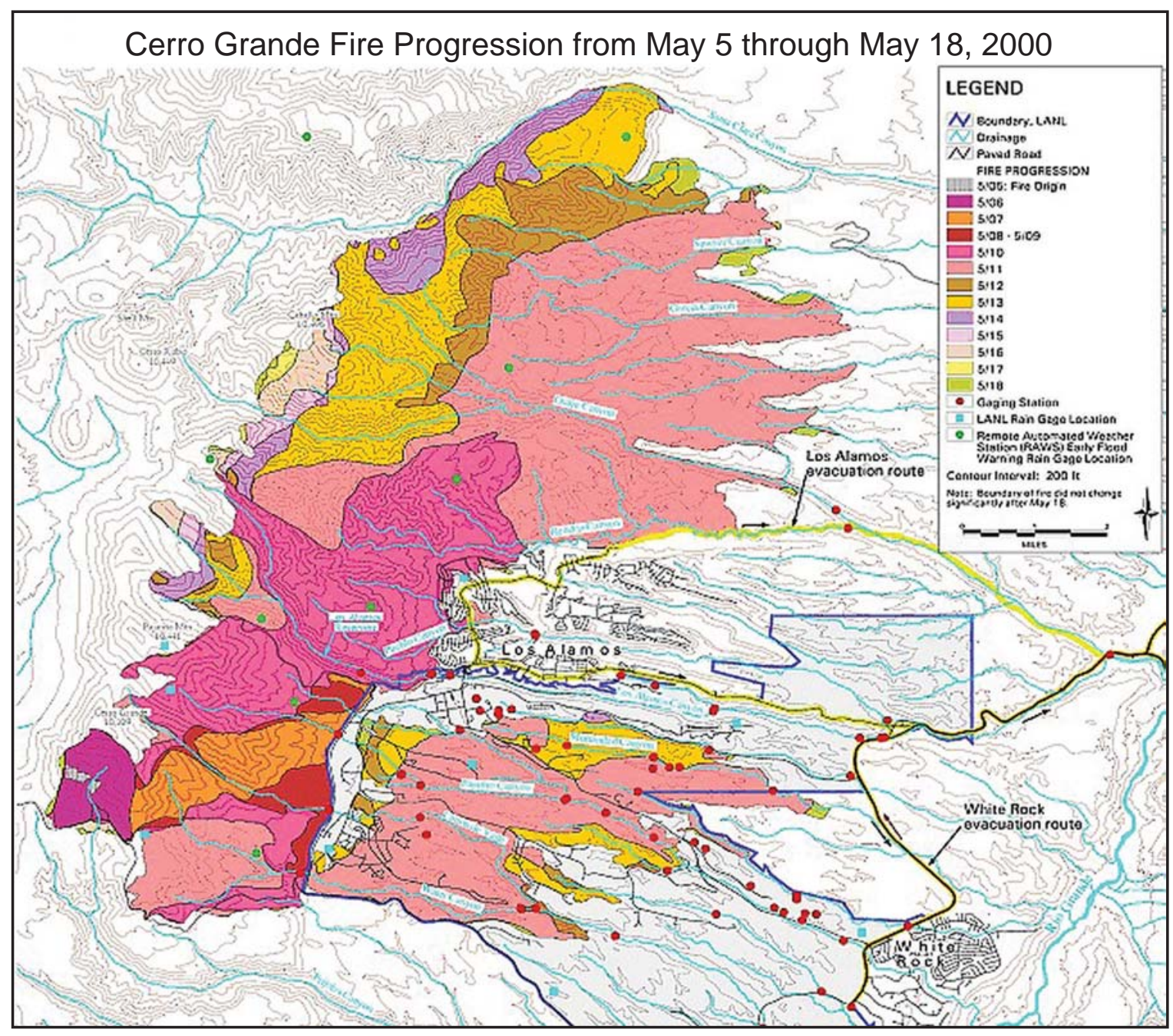

Fig. 29 - Cerro Grande Fire Progression Map showing areas burned on successive days. Note the especially large acreage burned on May 10 and 11. Gap in burn at lower left center along LANL boundary shows effectiveness of fuel break in that areas, which was breached on May 11 by airborne embers. The resulting second fire burned eastward while the main fire burned northeast. Note how close the second fire came to cutting White Rock's evacuation route. Red dots are streamflow-gaging stations emplaced after the fire. Green dots are automatic rain-gaging stations used to warn of rainfall with flash-flood potential (GISLab 2002). 
efforts there. The canyons on both sides of the facility and many trees close to the buildings, however, were burned.

\subsection{Transitional Operations}

The BAER team, which arrived May 15 while the fire still burned, was in Los Alamos for one month to develop mitigation strategies and to begin priority efforts to reduce erosion. A multiagency team of GIS technicians was brought as part of the team to create maps of areas to be rehabilitated. As LANL, too, began to

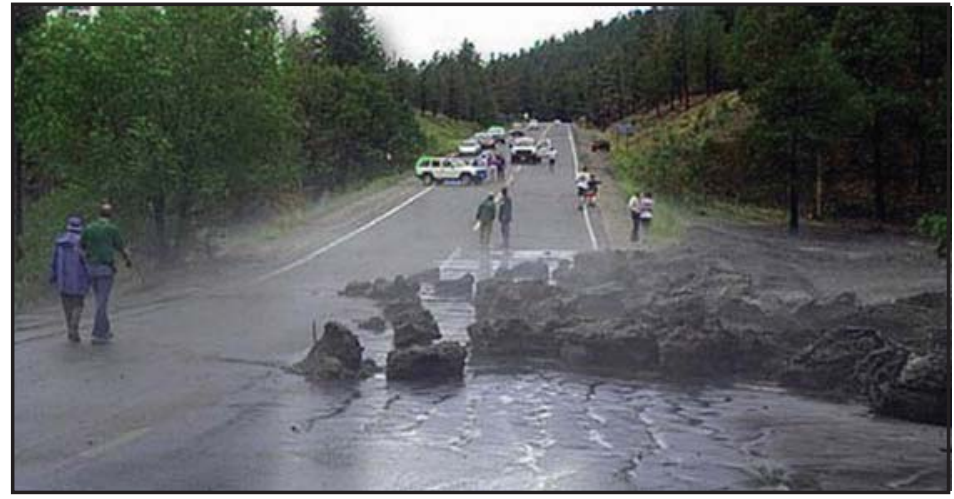

Fig. 30 - Flash flood debris flow on NM 501, June 28, 2000 (LANL). assess damage and plan recovery efforts, the need for infrastructure information and maps of fire severity increased dramatically. FIMAD, ESH-20, PM-1, and other GIS offices quickly responded, providing data and supplementing maps produced by the BAER team. Staff from Water Quality and Hydrology (ESH-18) and ESH-IM (Information Management) provided them with coordination, computers, and logistical support.

As the fire continued to burn in the mountains north of Los Alamos, ESH-20 provided the USFS's Incident Management Team with data on fuel loading and forest structure for use in a fire-behavior computer model, which helped fire managers to determine where to best position firefighting assets. The Ecology Group worked closely with the BAER team to determine burn severity patterns in the Laboratory's forests and grasslands (Fig. 29), and to provide information about ecological, biological, and archeological resources at LANL (Koch 2002).

The data, when fed into hydrological models, revealed which areas were subject to severe erosion unless they were protected with erosion-control measures. Steep slopes, for example, might need to be aerially sprayed with hydromulch, a sticky coating containing grass seed, fertilizer, and mulch. Less steep areas might be protected with bales of hay, straw-filled mesh tubes (called "wattles"), and straw mulch. Such measures were implemented on both Laboratory and non-Laboratory lands.

Modeling efforts during Cerro Grande required rapid collation of terrain data due to their being continually changed as a result of the fire. This required use of BAER team burn-severity maps in combination with digital vegetation maps, which were developed through assessment of the relationships between pre-fire vegetation and post-burn vegetation cover as a function of burn severity.

After White Rock residents were allowed to return, LANL environmental scientists from EES-15, ER, and ESH-18 began meeting in the White Rock Training Center to determine data and modeling requirements for assessing the

\section{Post-Cerro Grande 100-yr Floodpools}

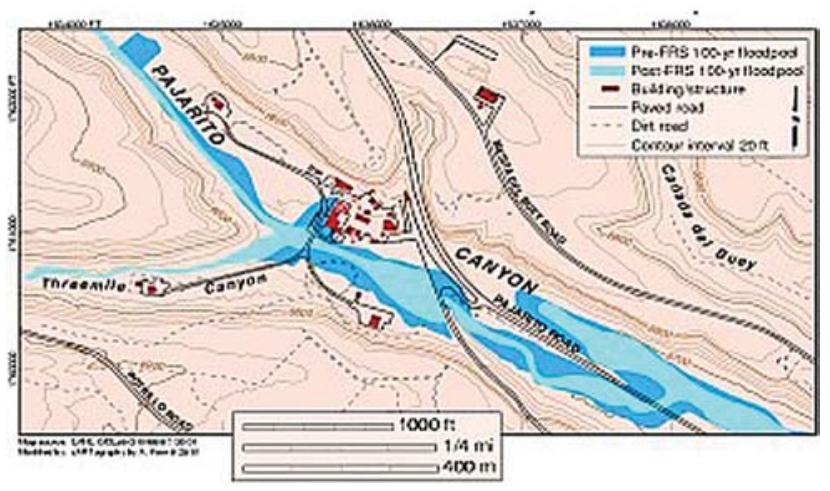

Fig. 31 - Predicted effect of flood retention structure (FRS) downstream in Pajarito Canyon. Flood modeling by EES-15 and ESH-18 (LANL). 


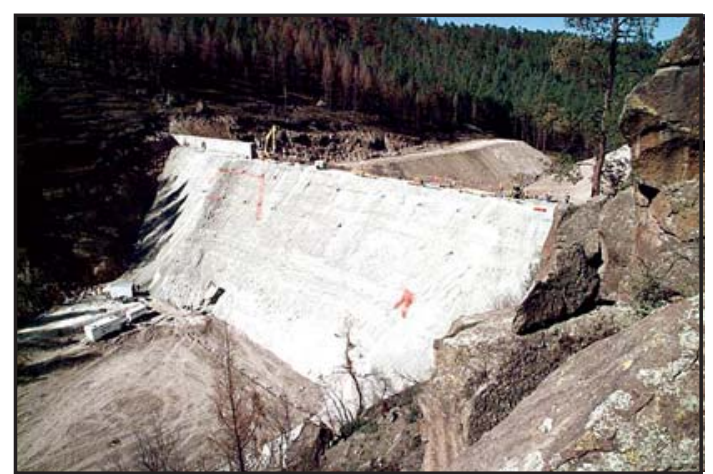

Fig. 32 - Corps of Engineers flood retention structure in Pajarito Canyon (LANL). hazards from floods, erosion, sedimentation, and contaminant mobilization. Such hazards faced county residents, LANL workers and facilities, and others in the surrounding area, and the work was of immediate importance due to the summer thunderstorm season. The team decided to acquire high-resolution topographic data from Airborne Laser Scanner (ALS), also known as LIDAR (Fig. 36), to enable high-resolution predictions of contaminant transport (Wilson 2002). The LIDAR data are frequently used in post-fire cartography and modeling due to their fine resolution of surface detail, showing even trees and bushes.

On June 2 the Laboratory director formed an Emergency Rehabilitation Team (ERT), composed of representatives from Laboratory groups, including the ER Project (for PRSs and sediment transport issues), ESH-18 (for storm-runoff matters), and ESH-17 (Air Quality). Representatives from other organizations outside the Laboratory also staffed the ERT, which conducted initial assessments of potential environmental impacts on Laboratory lands from the Cerro Grande wildfire.

GIS analyses and modeling, such as performed by EES-15, ESH-18, and ESH-20, were important for determining the immediate and long-term threat of flash flooding in the canyons (Fig. 30), soil erosion in potentially contaminated areas, and silting of the Los Alamos reservoir. The studies ultimately contributed to management decisions to close one large canyon-bottom facility found to be at increased risk from flash floods, construction of flood-retention structures by the U.S. Army Corps of Engineers, and improvements to bridges, culverts, and stream channels in the Laboratory and Los Alamos County.

Realization was growing that the devastated mountainsides not only had little remaining ground cover to hold rainwater but that the soil in places had also become water-repellant (hydrophobic). This effect was caused by the fire's intense heat, up to $1100^{\circ} \mathrm{C}\left(2000^{\circ} \mathrm{F}\right)$, which melted the resins in conifer needles that had carpeted the ground, thus forming a hard, impermeable layer (Foxx 2000). Such soil impedes seeds from taking root and delays recovery of grasses and other ground cover. Hydrophobic soil prevents rain from soaking into the ground and creates a risk of immediate runoff and flash flooding from even small rainfall events. Therein lay the danger - sudden flash floods caused by thunderstorms unleashing heavy rains on slopes that

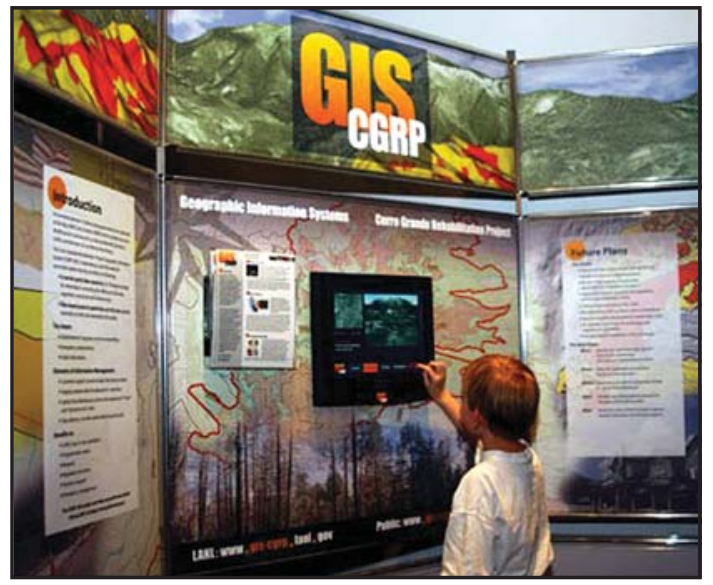

Fig. 33 - CGRP GIS display at the LANL Bradbury Museum (LANL). could not absorb or capture the water.

GIS technology played a major role in analyses of how canyon floodplains might be affected by post-fire runoff (Fig. 31). Such studies revealed the potential for storm water discharge rates of twoand-a-half to nearly six times normal (Buckley et al. 2002). Analyses warned of the possibility of 


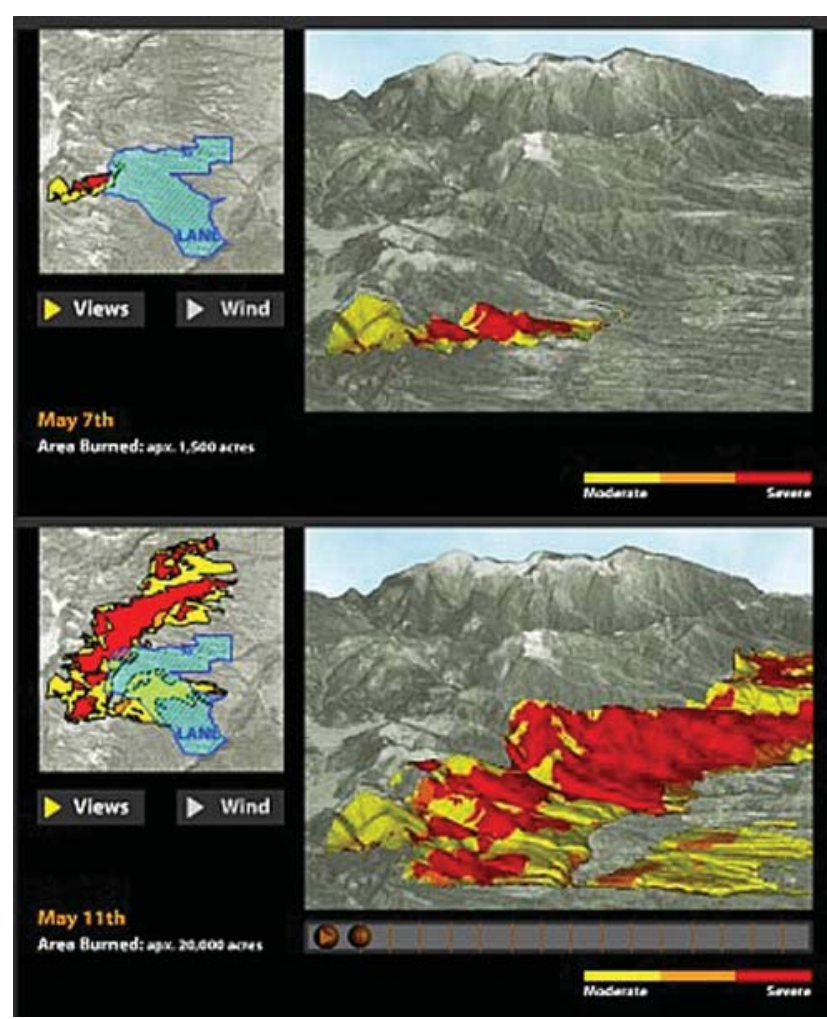

Fig. 34 - CGRP GIS web pages with animated 3-D views of fire progression and wind data for various days (GISLab). huge flashfloods that could reach White Rock, prompting the construction of a $20-\mathrm{m}(70-\mathrm{ft})$ high, $120-\mathrm{m}(390-\mathrm{ft})$ long concrete retention structure to slow such floods (Fig. 32).

Such concerns also led to decisions to restrict entry into flood-prone canyons, to mobilize teams to manually break up hydrophobic soils by raking, and to cover severely burned slopes with straw mulch. Fortunately summer rains in 2000 were light, and runoff was generally minimal the first year after the fire, but significant flood damage to roads and sewer mains in Los Alamos occurred in Pueblo Canyon the second year.

FIMAD and ER Project staff provided extensive data and maps about PRSs, particularly those located in burned areas, those actually affected by the fire, or those in drainage areas that might be subject to erosion. Several hundred maps were produced in a few weeks and all normal programmatic GIS work for the ER Project was halted for approximately 2 months, then slowly resumed (Bolivar 2002c). Various groups in EES

Division provided geomorphological and geological information to the BAER team and ER Project and did studies of post-flooding impacts on drainage, sediment transport, and migration of contaminants. GIS was used in these studies. Of particular note was the use of several remotesensing techniques, including AVIRIS (Airborne Visible Infrared Imaging Spectrometry) (Fig. 44) to determine the impact of fire on vegetation, erosion, forest-fuel loading, and soils. Such data were used to determine actual areas burned and types of vegetation affected, of use in modeling the future potential for fire, forest regrowth, and runoff (EES 2000).

\subsection{GIS SUPPORT OF THE CERRO GRANDE REHABILITATION PROJECT (CGRP)}

The Cerro Grande Rehabilitation Project was initiated soon after the fire to coordinate efforts to restore damaged infrastructure and property at the Laboratory and to mitigate hazards resulting from the fire, such as canyon flooding, erosion, the anticipated fall in the next decade of tens of thousands of dead trees and the hazard posed by the enormous quantity of partly burned but still flammable wood that remained. These threats, the ongoing mitigation measures to counter them, the Laboratory-wide remediation efforts to repair fire damage and ongoing environmental research about changes since the fire have increased the need for GIS at LANL.

In August 2000 the CGRP funded a new GIS, which is managed and operated by GISLab, the successor to FIMAD, on behalf of other CGRP subprojects and as an institutional GIS resource for both research and operations (Fig. 33). The CGRP also funded GIS work for several other tasks, including planning for forest thinning, delineation of floodplain changes, upgrade of GIS capabilities in a new EOC, mapping of infrastructure, and predictive fire modeling. These 
various GIS activities have improved LANL's disaster response capabilities, and have enabled a significant reduction in risk from future fires, floods, and other emergencies.
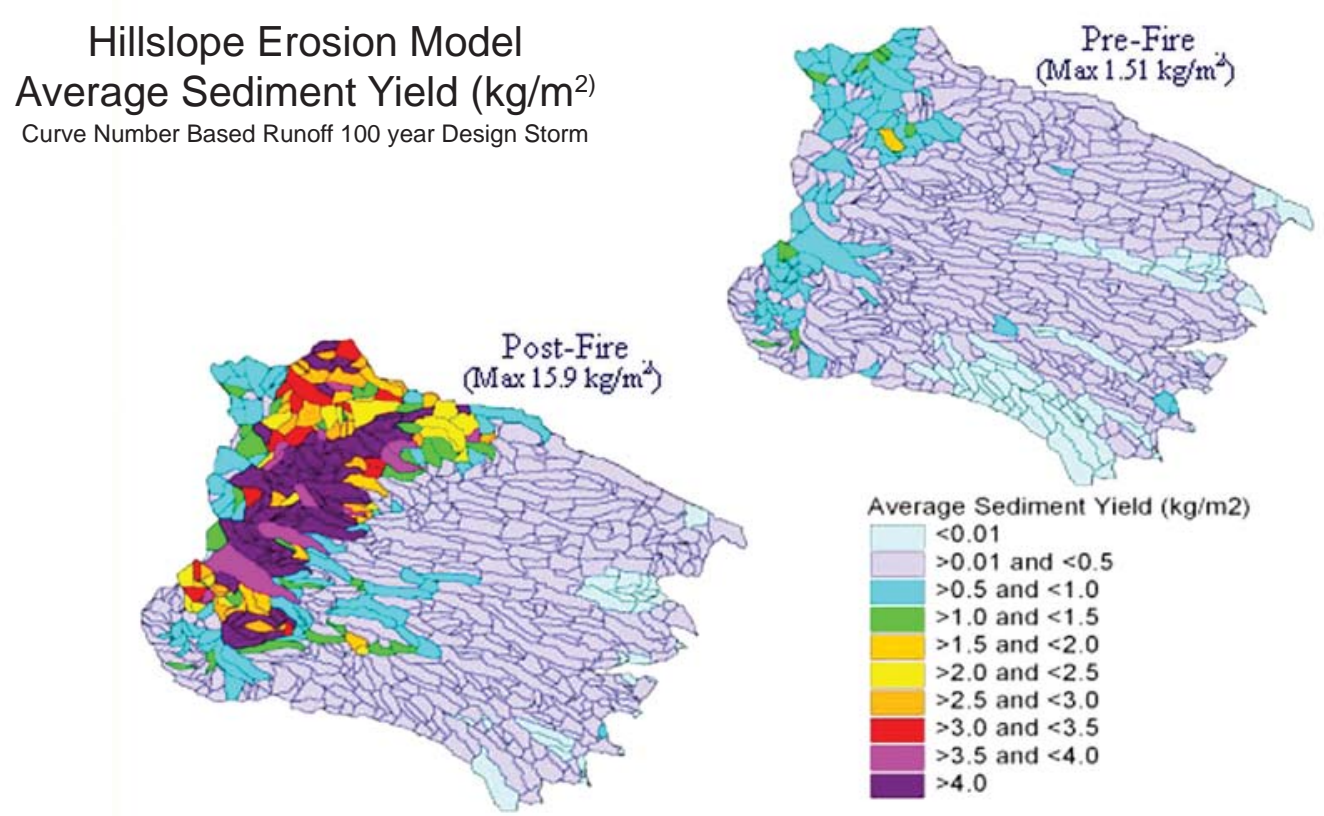

Fig. 35 - Example of erosion model results, used by EES-15 to predict sediment erosion and transport from burned mountain slopes into canyons. Results can be used to anticipate patterns of floodplain changes, downstream flood boundaries, and transport of contaminants (LANL).

\subsection{Cerro Grande Rehabilitation Project GIS}

The "CGRP GIS," a \$2.1M subproject, was undertaken to create a repository for geospatial data related to the Cerro Grande wildfire (Fig. 34), to prepare the institution for future emergencies, and to provide information about the fire to Laboratory researchers, managers, and the public (Mynard and Keating 2001; Keating et al. 2002a). A new GIS team leader, Dr. Paul Rich, was hired to lead the effort. The resulting CGRP GIS serves as an institutional resource. Rich came to the Laboratory with a strong

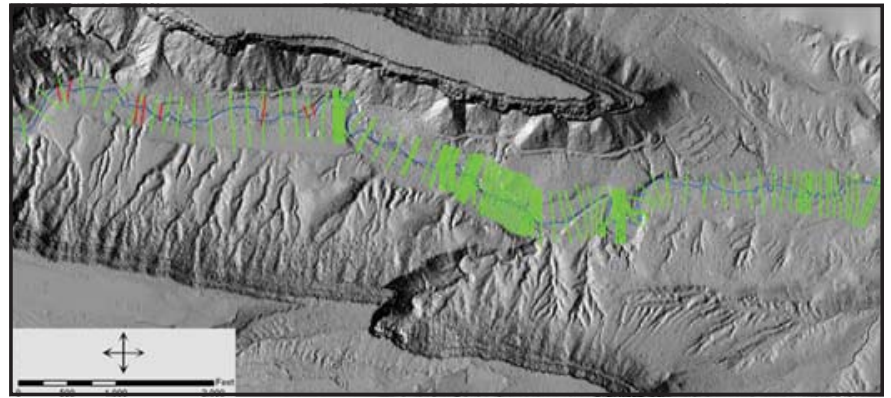

Fig. 36 - ALS imagery of a canyon. Used for detailed topographic data about floodplain's cross-sections, the green lines (LANL). academic background and extensive experience building GIS capability. He has championed the concept of institutional GIS, worked to unite the GIS community, and promoted excellence in GIS science and technology.

GISLab's spatial data warehouse is a major component of an enterprise, or organization-wide, GIS design (Figs. 39, 40). The design of the spatial data warehouse features large data-storage capacity, geospatial search functions, and web-based access to both spatial data and metadata. Metadata 
provide documentation about the spatial data (description, source, quality, access, etc.). Various enterprise GIS tools were developed for implementation of the spatial data warehouse, including a web-based system to track work and data. Policies and procedures were designed concerning data access, quality assurance, and metadata preparation (Witkowski et al. 2002, 2003).

\subsection{Use of GIS in Other CGRP Tasks}

A number of other subprojects of the CGRP utilize GIS, including sediment-transport modeling, forest management, and the new joint EOC.

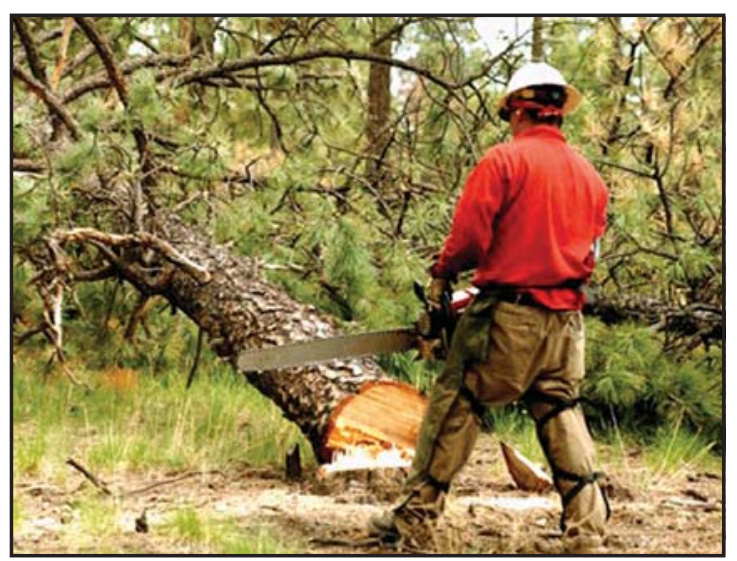

Fig. 37 - Tree-thinning project (LANL).

\subsubsection{Sediment-Transport Modeling}

The severely burned headwaters of many canyon streams resulted in flood-size and hill-slope erosion rates that increased by one to two orders of magnitude above pre-fire conditions. Scour and deposition in canyon channels, relatively stable prior to the fire, also dramatically increased. Some of these canyons contain legacy contaminants dating from the Manhattan Project era that could be remobilized by the post-fire floods. Computer modeling activities were therefore begun to assess the potential for offsite transport of contaminants during large floods (Fig. 35).

A GIS-based hill-slope erosion model was developed and applied to determine sediment inputs from burned uplands into the stream network. Models developed by the U.S. Army Corps of Engineers Hydrologic Engineering Center (HEC) were used to predict flood magnitudes, durations, and inundation areas. HEC6T, a one-dimensional sediment-transport model, was coupled to a contaminant-transport model to predict potential redistribution and offsite transport of contaminated sediments. Model predictions were tested against observed flood events. In particular, the canyon sediment/contaminant transport model was tested against high-resolution ALS topographic data (Fig. 36). The ALS data were collected before and after a large flash flood that occurred in Pueblo Canyon. These GIS data form the backbone of the model-testing process (Wilson 2002).

\subsubsection{Forest Management}

A fuel break along the west side of LANL, created after an earlier nearby fire, successfully prevented the Cerro Grande wildfire from directly spreading onto Laboratory property for 6 days until strong winds lofted burning embers across it on May 11 (Webb and Carpenter, 2001). The fire progression map in this report (GISLab, 2002) shows the effectiveness of the fuel break May 5-10 and the fire's spread from the small ignition point at the southwest corner of the Laboratory. The evident effectiveness of such fuel breaks led Laboratory managers to initiate a CGRP subproject to thin forests around Laboratory facilities to create "defensible space" and to create additional fuel breaks and fire roads. These efforts are designed to impede the spread of future fires across LANL property and to protect Laboratory infrastructure. Thinning is also underway along highways that border the Laboratory, thus helping to protect Los Alamos and White Rock (Fig. 37). 


\subsubsection{New Joint Emergency Operations Center}

As is typical in emergencies, the Cerro Grande wildfire revealed problems and inefficiencies to be resolved by emergency and organizational managers and operations personnel. Some issues were administrative, some were technical, and others related to the Laboratory's physical layout and infrastructure. Many issues were related to the ability to access and communicate information. A number of these issues led to the Laboratory's decision to relocate and build a new, much larger EOC at TA-69. In order to improve interagency communication it will be a joint facility for use by LANL and Los Alamos County (police, fire, ambulance dispatch), with participation as needed by the neighboring pueblos, national guard, state police, Red Cross, DOE, and New Mexico Emergency Management representatives (LANL Newsbulletin 2002).

The new facility will address problems of computer network access and reliability by having its own data mirror to capture regular "snapshots" of the Laboratory's changing infrastructure. This will provide managers an internal, up-to-date compilation of facility-related information rather than their having to depend on uninterrupted access to numerous, project-specific servers dispersed around the Lab (Coffman et al. 2000a). The data mirror will permit the creation of detailed maps for use by emergency personnel. It will be further enhanced by relay of digital information, maps, and images to field personnel by means of improved radio links (Hart 2002).

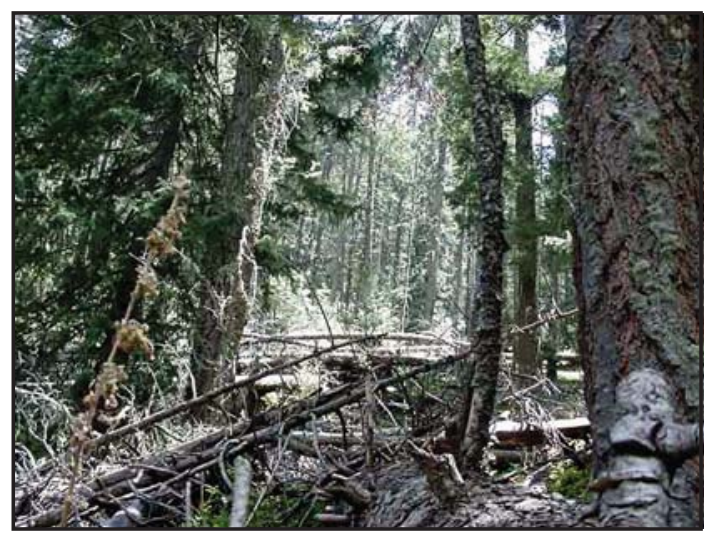

Fig. 38 - Dense forest fuels in the Jemez Mountains (USFS).

\subsection{Special Achievement Award for Cerro Grande GIS Efforts}

A Special Achievement in GIS (SAG) Award was presented to GISLab and colleagues of LANL and the BAER team on July 11, 2002, in recognition of GIS efforts during the fire and afterwards in support of the CGRP (LANL 2002). Environmental Systems Research Institute (ESRI), a leader in GIS technology, presented the award (see the Appendix for details).

\subsection{LESSONS LEARNED}

The Cerro Grande wildfire taught many lessons with respect to use of GIS in emergencies, some that were immediately apparent and others that were evident only later and upon reflection. These include large issues of institutional significance, some that relate to working relationships, and others regarding details of emergency preparedness. The following lessons-learned have been gleaned from discussions with many of the participants of the Cerro Grande wildfire experience, from personal observations, and from various LANL documents.

\subsection{GIS provides an integrating framework for assessing natural and human hazards in a landscape context.}

The Cerro Grande wildfire reminded us that LANL exists within the context of a larger landscape, subject to hazards posed by natural phenomena and human activities. The forests surrounding Los Alamos are part of a fire-dominated ecosystem, in which lightning and human-caused fires regularly occur. The potential magnitude of individual fires is increasing due to decades of fire suppression. 
Only by viewing LANL within its geographical and ecological setting can emergency response be tailored to these real risks. GIS provides an integrating framework for assessing natural hazards, security issues, and emergency response. During the Cerro Grande wildfire, GIS was used "on-thefly" for this purpose. Emergency preparedness requires that we expand our ability to view Los Alamos within the larger landscape.

\subsection{A strong GIS capability within LANL is needed for emergency response.}

Laboratory GIS staff rebuilt the necessary database and established an effective emergency GIS facility during the fire. This highlights the importance of a strong GIS capability. There remains a need for more GIS technical experts at LANL. These personnel should be experienced at solving unique and complex problems, have the flexibility to work in emergency situations, and have the understanding both of generic GIS systems and of the LANL data set, specifically. Laboratory GIS professionals, in many cases unavailable due to the evacuation, were already limited in number. Those who were available were consequently greatly overworked during the emergency. The bottom line: by maintaining a strong GIS capability, with expert staff who are experienced with solving novel problems, $L A N L$ can be prepared for future emergencies.

\subsection{Coordinated emergency plans are needed for GIS operations.}

Lack of contingency plans for offsite GIS operations during emergencies delayed the acquisition, processing, and distribution of necessary data and maps. Without the extraordinary innovation, personal initiative, and spirit of voluntarism of participants - plus a large degree of good fortune GIS support to internal and external decision-makers would have been problematic under the particular emergency conditions of the Cerro Grande wildfire. Though such crises tend to bring out the best efforts of staff, pre-planning is important for effectively dealing with large-scale disasters, including, it should be emphasized, with terrorist attacks.

The general lack of emergency plans by LANL's GIS organizations was perhaps due to 1) lack of formally defined roles for GIS in emergency management, and uncertainty (expressed by emergency managers) as to which institutional data might be needed; 2) an unstated assumption that evacuation of the entire Laboratory was so unlikely that local, facility emergency plans were generally sufficient. Such a perception, though historically valid, has been shown by the Cerro Grande wildfire to be unrealistic, due in part to the expanding risk of large wildland fires brought about by the everincreasing density of area forests and the current severe drought conditions. Though the Cerro Grande wildfire was deliberately initiated as an attempt to reduce the forest's excessive fuel load, seasonal lightning storms could just as easily have been the ignition source. Indeed, much of the Jemez Mountains are as densely forested as ever (Fig. 38) and remain extremely prone to major wildfires.

Fire was not present on Laboratory property for the first three days of the Laboratory shutdown, which would have allowed time to take precautions to protect or relocate essential equipment, computers, and data resources. This was not permitted except in a few cases, increasing the chance of loss of such assets. Better coordination and communication between emergency and line managers can deal with this issue, which should be addressed in future emergency plans. A procedure is needed to allow selective re-entry by employees for emergency preparations, including the removal of equipment, records, and data to safe zones either on or off Laboratory property (Coffman et al. 2000a). Several fireproof structures might be constructed on Lab property for 
protected storage, and offsite office space could be leased for conducting important business functions during the emergency.

Emergency plans should identify equipment, software, and key information that should be taken to predetermined, alternate work locations. Such items include portable computers that have been loaded with GIS software and important data, necessary peripherals, contact information for key personnel, institutional credit cards, password security devices, and key reference materials (Davenhall 2002). These are critical to the timely establishment of a GIS capability offsite.

Emergency plans should consider sources for additional staff. For evacuees, the immediate needs of safety, lodging, family, and personal matters must take precedence over employment duties. It is therefore unlikely that personnel who have been evacuated can report for duty for several days, or until their personal situation stabilizes. This means that staffing for emergency efforts will likely require personnel from outside the affected area, as was the case for FIMAD.

\subsection{GIS and other employees need a method to report their whereabouts and to receive authoritative information and instructions during an evacuation.}

Three aspects of the evacuation of Los Alamos County created a low probability of GIS employees finding each other. First, residents of Los Alamos, the first town to be evacuated, who arranged to stay in White Rock were evacuated twice and thus had little time to inform others of their alternate location. Second, all residents were evacuated, so those who desired to inform others in the county of their plans might find no one home to receive the information. Third, the evacuation of White Rock occurred without advance warning in the middle of the night, so residents were too busy packing and departing to inform others of their destination.

Evacuees were no longer reachable by their home and work telephones, thus were essentially "missing" unless they 1) had a cellular phone and 2) those wishing to contact them knew their number. In most cases, initial contact was made by the evacuees themselves to someone who lived outside the evacuated area, which was the method used by some ER Project and FIMAD staff to find each other. No mechanism existed in the Laboratory or county for employees or residents to leave their location information, other than as messages on office voicemail or home answering machines, which would probably be unheard.

There was no efficient overall collection of information about evacuees from among the various shelters, churches, Red Cross centers, television phone centers, LANL Outreach Office phone center, and several web databases that existed. Knowledge about (and therefore use of) these diverse data resources was haphazard and overly dependent on one's location, choice of news outlet, and timing. Managers and their employees thus had no assured way to find each other, so the organizational structure and most functions of the Laboratory (as well as Los Alamos businesses) were essentially not staffed for 14 days. Though LANL's emergency functions continued, only a few organizations were able to regroup sufficiently to carry on their mission during the Laboratory's shutdown. The Laboratory thus needs a system for contacting and being contacted by employees during a full evacuation (Coffman et al. 2000b). The system might include phone, e-mail, and web components.

Such a system could also be used for providing authoritative information to users, since media reports were found to be sometimes unreliable (Coffman et al. 2000b). Reports during the Cerro Grande wildfire about the fate of particular worksites, of great interest to employees (but also subject to considerations of site security), were generally limited and not sufficiently detailed for employees 
to have a clear idea of what damage to expect upon their return to work (Coffman et al. 2000a). A website for use just during emergencies has been developed by the LANL Public Affairs Office (CER-20) to provide updated official information.

\subsection{GIS data should be complete, backed-up, and available during an emergency.}

Access to information is imperative in a crisis, and effective use of GIS during an emergency requires information from many sources. Ideally these data should be complete, accurate, authoritative, and documented with metadata. Data resources should therefore be coordinated by data users and providers to resolve such issues in advance of an emergency. During the fire incomplete access to data, and data that was not current or complete, created problems at DOE Albuquerque and at the LANL EOC (Keating et al. 2002b, 2003). Spatial data about the Lab that was initially used consisted of 1999 data on Laboratory roads and buildings that had been requested by and archived at the Bechtel Nevada Remote Sensing Laboratory to prepare a book of maps of DOE facilities (Valencia 2002). Such dated or partial information does not provide a true backup of frequently changing data about complex details of Laboratory infrastructure and land characteristics. Nevertheless, GIS staff did an excellent job with data obtained from LANL and non-LANL sources.

Data and project records typically were backed-up in the same or an adjacent building, both of which might be at risk during a site-wide fire such as Cerro Grande. At TA-48, for example, fire melted the plastic skirting on a transportable building containing the backup servers and important paper records for a major DOE project. The structure fortunately did not ignite. Backup copies of important or irreplaceable information should therefore be stored at an entirely different LANL site as well as at a secure, off-site location (Coffman et al. 2000b). This issue affects almost all Laboratory organizations, and is relevant to GIS work in general.

\subsection{GIS procedures must be adaptable to the needs and circumstances of the emergency.} Conditions under which GIS technology is used may change quickly and radically during an emergency; GIS needs during the Cerro Grande wildfire were immediate, unique to the situation, and changed daily. These needs required unique, rapid solutions. GIS staff may not be able to use the standard procedures of normal operations, and managers may be faced with unexpected data needs. Both must be flexible and highly innovative in order to adapt to the chaos and uncertainty that occur during emergencies. It thus becomes important for staff to understand not just how to perform certain tasks, but why they are done in a certain fashion. Such understanding gives GIS personnel mastery of how to quickly adapt their tools, technology, and methods to very different needs and conditions. Similarly, knowledge of alternative data resources that may be available during an emergency helps alleviate the absence or failure of normal data resources. An example of the successful use of other data sources was Sandia's request to members of the NMGIC for base maps of the Los Alamos area.

\subsection{The GIS community needs to more fully coordinate efforts.}

GIS capabilities reside in many parts of LANL. At a grassroots level there are good relations, appropriate division of effort and specialization, and a sharing among staff of data, technical expertise, and capabilities. However, at an organization level there are issues of territoriality, "stove piping " of efforts, and a general reluctance to share programmatic data (technically owned by DOE rather than by the Laboratory organizations that obtained the data). There have been no institutional formalization of the GIS community, explicit formal mechanisms for data sharing, or consistent data-management practices among organizational units. These problems are typical of organizations 
at this early stage of GIS maturity but the fire showed how important it is for staff to work together and how effective GIS can be when cooperation is good (Keating et al. 2002b, 2003).

Much of the efficiency and effectiveness of GIS efforts during the fire were due to personal relationships developed prior to the emergency among data providers, users, and GIS staff. These were based on interactions that tended to bridge organizational subdivisions. Efforts should be expanded to further communication and mutual support among GIS personnel, both internal and external to the participating organizations.

At LANL, these efforts since the fire include communication among members of both the LANL and the New Mexico GIS user groups via web, e-mail, and joint meetings; inclusion of members from the Santa Fe National Forest, Bandelier National Monument, and Los Alamos County in the LANL GIS Users Group; coordination among the GIS community for mutual training and national-level speakers; participation in the DOE ad hoc GIS Users Group; and closer interaction among GIS staff at Los Alamos and Sandia National Laboratories. Indeed, this paper is a result of collaborative efforts among GIS participants in the Cerro Grande wildfire.

DOE facilities should begin sharing geospatial data, a goal of the DOE Headquarters Chief Information Officer. Lack of mechanisms for such data sharing caused the EOC at the DOE Albuquerque Field (now Operations) Office (DOE/AL) not to have current maps of the LANL facility, either in paper or digital form. At a minimum, the Albuquerque EOC should maintain a set of updated maps of each facility for which the DOE/AL has responsibility. GIS efforts between LANL and other DOE GIS resources, such as Sandia National Laboratories, need to be more coordinated.

The DOE/AL should also have a GIS point of contact at each facility under their responsibility, and each facility, in turn, needs GIS points of contacts and an emergency "phone tree" that lists state and federal agencies who could provide mapping information in an emergency situation. In addition, preapproved access to data held by these agencies should be in place. Data at the National Imagery and Mapping Agency (NIMA), for example, was unavailable during the fire due to lack of an existing DOE-approved protocol to obtain it.

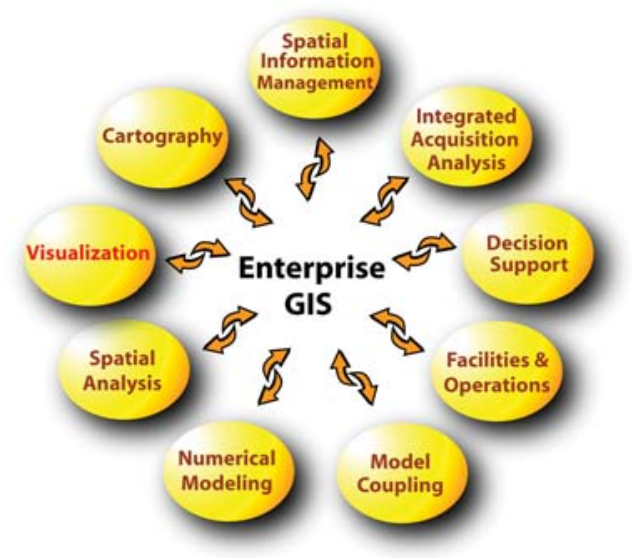

Fig. 39 - Enterprise GIS makes data and analysis capabilities available at an institutional scale (Witkowski et al. 2002, 2003).

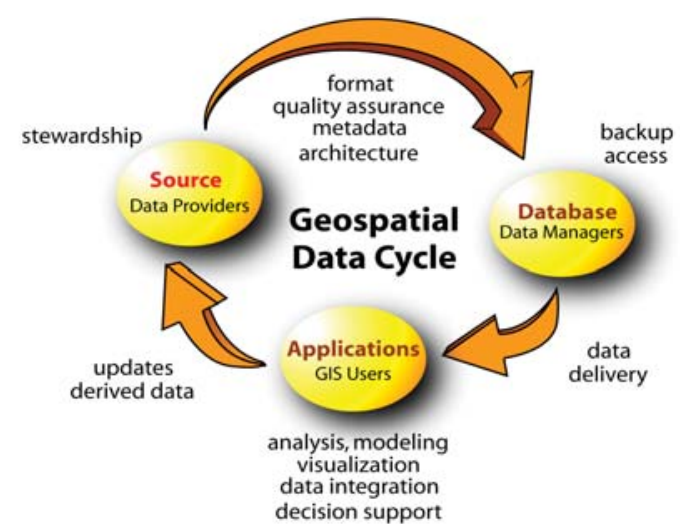

Fig. 40 - A complete geospatial data cycle ensures that data flow efficiently between source, database, and applications (Witkowski et al. 2002, 2003). 


\subsection{Institutional GIS resources should be more fully integrated into LANL operations.}

The diverse GIS assets and resources at LANL currently operate independently and in isolation, as they did during the fire. To facilitate a coordinated approach to emergency management and other institutional needs they should be more fully integrated into all levels of operations - including facility planning, risk and needs assessment, emergency planning and response, site security, environmental restoration, communications, facility operations, community outreach, and interagency interactions - as well as into programmatic research. Such integration is more likely if 1) the staff is continually aware of evolving GIS technology and has a high level of expertise in GIS, 2) there is institutional data sharing, and 3) appropriate GIS support is available for both programmatic work and operations. Awareness of the power of GIS has been increasing at LANL, particularly since the fire, but many managers and staff still do not understand the technology. Many recognize its importance but, because of this lack of knowledge, GIS is not yet well integrated. LANL should also participate in research and development of GIS technology, including enterprise GIS (Figs. 39, 40) to enable it to better meet unique user and institutional needs (Keating et al. 2002b, 2003).

\subsection{Key infrastructure information and geospatial data should reside on a LANL central computer repository — a data warehouse.}

Dispersed and unavailable information, and the fact that there was no official version for various key data, were repeatedly cited as a problem during the Cerro Grande wildfire. Emergency and facility managers needed a diversity of information scattered on numerous servers, many of which were not easily accessed (Coffman et al. 2000a). The data were in many formats, used various brands and types of software, had uncertain or unknown quality and completeness, and, in most cases, had no metadata. Staff that might know how to access or interpret the information was usually not present.

A reliably accessible central repository for important information and geospatial data about individual facilities and the Laboratory is needed (Keating et al. 2002b). This need is being addressed both by the CGRP GIS and by the data mirror being planned for the new EOC. At present the CGRP GIS is in transition from being a repository for fire-related data to a broader use as an environmental data repository. The EOC data mirror is envisioned as a repository of facility information and would be supplemented by data held in the CGRP GIS, such as flood zones, contaminant data, vegetative patterns that might affect fire risk, etc. (Hart 2002).

\subsection{THE FUTURE OF GIS AND EMERGENCY MANAGEMENT}

The Cerro Grande wildfire was a serious regional emergency that provided neighboring governments and the Laboratory with important lessons about how to deal with large-scale disasters. Such lessons are being incorporated into local, state, federal, and LANL disaster planning so that future emergencies will be handled with improved procedures, communication, and coordination. The strong cooperation that has developed among the various entities involved in emergency response, care of evacuees, and rehabilitation efforts is heartening, and has already borne fruit in such things as the joint LANL-county EOC. In regard to the use of GIS technology in emergency management, the following institutional suggestions seem warranted.

\subsection{LANL GIS Steering Committees}

Development of an enterprise GIS capability at LANL and a new appreciation by management of GIS's power for aiding decision-making are leading to considerable rethinking of how to best develop an institutional role for GIS within the Laboratory. In September 2001, GISLab team leader 
Paul Rich gave a presentation to the LANL Chief Information Officer (CIO) Policy Board, recommending the designation of an institutional GIS and formation of a Laboratory-wide GIS steering committee. This led to the formation of GIS working group that offered recommendations concerning LANL institutional GIS in January 2002. The CIO responded in May 2002 by forming two LANL GIS steering committees, one technical and the other managerial, to deal with such institutional issues as geospatial data standards, data quality, data sharing, administrative oversight, organizational responsibilities, institutional policies, and institutional funding. The steering committees, with representation across the Laboratory, provide a venue to express ideas, concerns, and possible solutions to long-standing issues regarding GIS. A major charge is to develop and implement a LANL spatial information management plan.

\subsection{Institutional Policies and Standards}

The current group of divergent, independent GIS facilities at LANL has come into being over many years in order to meet the needs of various unrelated projects and Laboratory functions. The fire revealed the need to have more compatibility and coordination among these facilities as to software and data standards; data sharing (with appropriate protection of sensitive information); more complete documentation and metadata for institutionally important datasets; and coordinated policies, procedures, and standards for using the data. The two LANL CIO steering groups and the DOE ad hoc GIS User Group provide a first step in such coordination.

\subsection{Emergency Planning}

A Laboratory site-wide evacuation plan is under development in 2002, presenting an opportunity to coordinate among the Laboratory's facility- and function-based emergency plans and Los Alamos County's emergency plans. The new Joint EOC will

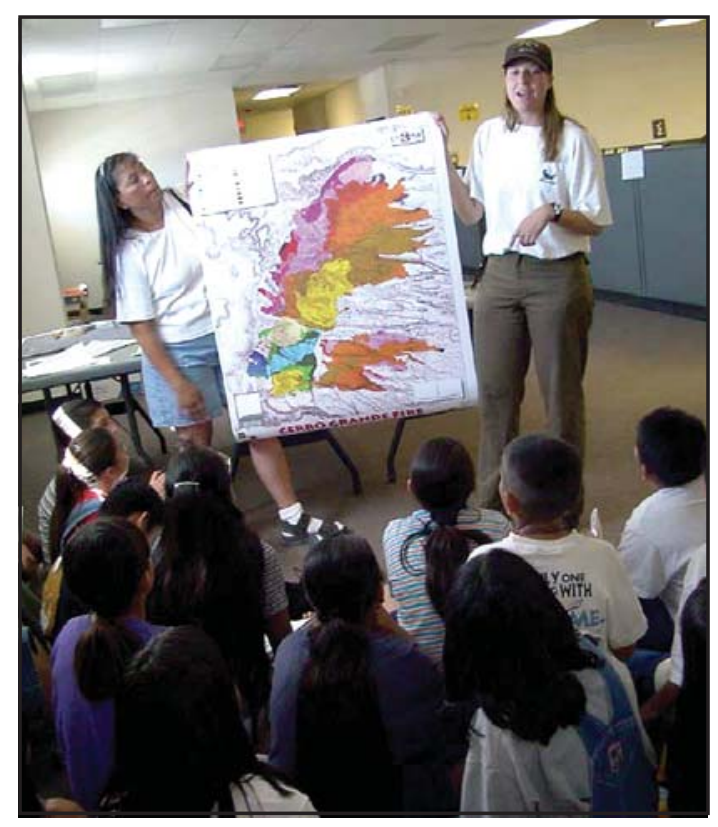

Fig. 41 - Map of Cerro Grande wildfire shown to young students (USFS). enable smoother integration of these plans. In addition, and in consideration of the continuing fire threat, Lab GIS facilities should be formally assigned roles for supporting emergency management. Participating GIS organizations should, therefore, develop emergency plans to enable them to perform these roles in a coordinated fashion. GISLab has developed a draft Continuity of Operations Plan for continuing GIS efforts during a site evacuation or other emergency.

\subsection{Offsite Backup of Institutional Data}

Because information about Laboratory infrastructure and property are important for emergency management and programmatic work, such data should be regularly backed-up offsite. Such an effort is now in place for LANL business data. Sharing and mirroring of important data would enable participating DOE facilities and the DOE to protect and use the data for various DOE-wide purposes, including facility security, site planning, emergency management, and research collaboration. GIS spatial data for key infrastructure information could be mirrored between LANL and other DOE facilities, such as Sandia National Laboratories. The Bechtel Nevada Remote Sensing Laboratory 
already maintains emergency GIS data for the DOE complex, but these data are not always up-todate and complete.

\subsection{LANL Spatial Information Management Plan}

For LANL, a carefully formulated spatial information management plan is needed to ensure both sound technical design and best business practices with respect to institutional GIS (Keating et al. $2002 \mathrm{~b}, \mathrm{c})$. Issues to be addressed include development of standards for geospatial data stewardship and core GIS capabilities, design of spatial information management infrastructure for data security and access, cleanup of legacy data and preparation of metadata to comply with OMB Circular A-16, and definition of distinct and integrated roles for the various contributors to institutional GIS along with formulation of necessary policies and standards.

\subsection{Coordination Within the DOE Complex and with Other Organizations}

The Cerro Grande wildfire revealed the need for closer coordination of disaster response among state, federal (Fig. 41), and national laboratory GIS facilities. Interaction among LANL GIS users has increased through the LANL GIS Users Group, with the state government by its New Mexico GIS Advisory Committee (GISAC), and between LANL and Sandia GIS facilities at the staff level (this paper being one example). The LANL Joint EOC will increase coordination among local governmental organizations.

Grassroots efforts in the DOE GIS User Group and top-down efforts through the DOE headquarters CIO office have highlighted the benefits of coordinating GIS efforts across the DOE complex. Furthermore, the Office of Management and Budget (OMB) has applied increasing pressure on DOE to comply with federally mandated requirements for geospatial data, as required by OMB Circular A-16. There is also a major push to enhance electronic data exchange in accord with the federal government's increasing use of electronic communication for its organizational and public interactions, reflected in the new term "e-government." The President of the United States

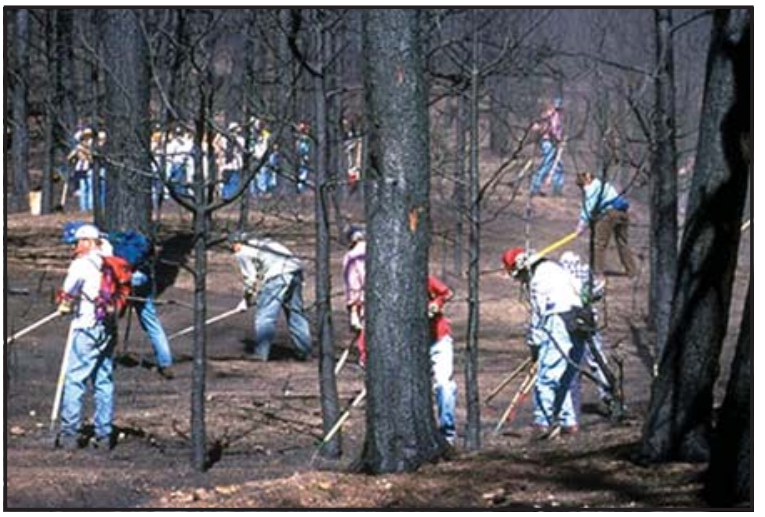

Fig. 42 - Volunteers raking hydrophobic soil (ESH Division, LANL, 2000) has recognized twenty-four e-government initiatives, including the "Geospatial One-Stop," which promotes sharing and accessibility of geospatial data in government agencies. This highlights the need for increased coordination of GIS efforts within the DOE complex and with other government agencies. The DOE CIO selected GISLab team leader Paul Rich to serve as the LANL representative on a recently formed DOE GIS Core Team, and to work with a smaller team to help write the DOE Geospatial One-Stop initiative.

\subsection{SUMMARY}

\subsection{Key Events}

The May 2000 Cerro Grande wildfire spread from an NPS-prescribed fire that was an attempt to reduce forest fuels. Strong winds drove the flames across the eastern side of the Jemez Mountains of northern New Mexico into Los Alamos National Laboratory and the city of Los Alamos, destroying Laboratory 
infrastructure, homes, and large areas of forest. Firefighting and emergency response continued for 2 months as the fire consumed approximately 17,400 ha (43,000 acres).

GIS played a significant role in the firefighting efforts, and many personnel from the Laboratory and other organizations worked under demanding conditions to support emergency managers. Subsequent to the fire, LANL staff provided logistical support and data to the multiagency BAER team and helped them provide GIS data and maps to Laboratory, federal, state, county, tribal, and municipal organizations. Laboratory GIS staff continues to work with researchers, operations personnel, and managers to understand and deal with the tremendous environmental changes caused by the fire.

\subsection{Lessons Learned}

- GIS provides an integrating framework for assessing natural and human hazards in a landscape context.

- A strong LANL GIS capability is needed for emergency response.

- Coordinated emergency plans are needed for GIS operations.

- GIS and other employees need a place to report their whereabouts and to receive authoritative information and instructions during an evacuation.

- GIS data should be complete, backed-up, and available during an emergency.

- GIS procedures must be adaptable to the needs and circumstances of the emergency.

- The GIS community needs to more fully coordinate efforts.

- Institutional GIS resources should be more fully integrated into LANL operations.

- Key infrastructure information and geospatial data should reside on a LANL central computer repository - a data warehouse.

\subsection{Future Directions}

The growing maturity of GIS, together with lessons learned from the Cerro Grande wildfire, will lead to greater standardization and a better-integrated, more-coordinated approach to using this technology at LANL and among other DOE laboratories and facilities. This includes greater definition of the role of GIS in emergency management. Key institutional data are being identified and discussions are underway for potential offsite storage. Institutional GIS steering committees are developing policies and standards for spatial data. The interagency response during the Cerro Grande wildfire highlighted the need for closer coordination among the many GIS groups in the region, and professional ties within this community, both at LANL and within the DOE complex, are being strengthened by formal and ad hoc working groups, and by attention of the DOE CIO office, to promote the sharing of resources and ideas.

\subsection{CONCLUSIONS}

The Cerro Grande wildfire was an event that created major change for LANL, Los Alamos, and the surrounding region's environment, economy, societal relationships, and governments. It has motivated numerous changes in the way the region's organizations interact and coordinate, and has 
produced a bonding and a new mutual appreciation among the diverse cultures and towns of northern New Mexico (Grieggs 2001).

GIS played a valuable role in the response to the fire, and many lessons can be learned from the experience. Such lessons can invigorate and enhance the use of this important technology throughout the Laboratory and elsewhere. The organizations that administer portions of the Jemez Mountains and Pajarito Plateau are working in closer coordination, harmony, and unity of purpose to protect the area from future fires and to better understand the natural processes of disaster recovery (Fig. 42). We in the GIS community already see this happening.

The fire's legacy of painful personal losses, and disfigurement of the once lush mountainsides above Los Alamos (Fig. 44) will, in time, be healed by rebuilding of homes and lives and by the renewal of the landscape with different patterns of vegetation (Fig. 43). Relief efforts since the fire by regional, national, and even international governments, communities, businesses, and individuals are truly amazing and unforgettable to those of us who experienced the fire. The sense of mutual regard this has engendered may be the most valuable result of the fire, and it is one to be nurtured.

\subsection{ACKNOWLEDGEMENTS}

Many people helped in gathering stories and checking accuracy for this report. The authors have tried to capture the feel of the experience, not just relate a sequence of events. We gratefully thank those who have related personal experiences and provided narratives of the complex web of activities that occurred. This compilation brings together many parts of the Cerro Grande story of which the contributors, who experienced it under stress and fatigue, knew only portions. Any errors are unintended and are the responsibility of the authors. The many individuals involved in GIS efforts during and since the fire greatly deserve the recognition of the ESRI "Special Achievement in GIS" Award. We, too, express our gratitude to them.

We wish to thank in particular Steve Bolivar, Julie Canepa, Carl Davenhall, Rick de Saussure, Tom Garrison, Marcia Jones, Steve Linger, Lynn McDonald, and Doug Walther for information about FIMAD and ER activities. Dave Howard and John Huchton provided information about events at the LANL EOC. Cathy Wilson and Peter Beeson related EES-15 efforts; John Huchton and Steve Koch told of ESH-20 activities; and Harold Salazar and Richard Gonzales provided information on JCNNM's role during and subsequent to the fire. Ken Mullen discussed liaison with the BAER team, as did Joan Stockum. Orval Hart discussed information capabilities of the new EOC. We also thank everyone who reviewed the draft report and provided clarifications.

Special thanks go to Steve Mee and the staff of the Cerro Grande Rehabilitation Project for their guidance, administrative oversight, and financial support for the CGRP GIS and other recovery and mitigation efforts at LANL. Such work was funded through emergency funds provided to DOE and LANL to remediate damage and to address demonstrated vulnerabilities associated with the Cerro Grande wildfire. 


\subsection{REFERENCES}

\subsection{Publications}

Buckley, Kevin J., J. Walterscheid, S. Loftin, and G. Kuyumjian. 2002. Progress Report on Los Alamos National Laboratory Cerro Grande Fire Rehabilitation Activities One Year After Burned Area Rehabilitation. Los Alamos National Laboratory report. LA-UR-02-4921.

Coffman, Cindy, D. Hall and T. Salazar-Langley. 2000a. Cerro Grande Fire - FWO \& Facilities Lessons To Be Learned Report. Los Alamos National Laboratory report, FWO LL REP.6.28.00: v2, 28 June 2000. LA-UR-01-1304.

Coffman, Cindy, D. Hall and T. Salazar-Langley. 2000b. Cerro Grande Fire - Laboratory Recovery Lessons To Be Learned Report. Los Alamos National Laboratory report, AFRC-RECV.RPT 11/ 00, 28 Nov. 2000. LA-UR-01-1305.

Earth and Environmental Sciences Division. 2000. Progress Report 1998-2000. Los Alamos National Laboratory Progress Report. LA-13825-PR.

Environmental Safety and Health Division, Los Alamos National Laboratory. 2000. For the Seventh Generation - Environment, Safety, and Health at Los Alamos National Laboratory: A Report to Our Communities, 1999-2000, Volume IV. LALP-00-133.

Foxx, Teralene S. 2000. Out of the Ashes, a Story of Natural Recovery. Los Alamos National Laboratory report. LALP-01-02.

GISLab, Los Alamos National Laboratory. 2002. Cerro Grande Fire Progression from May 5 through May 18, 2000. Plot ID\# G110345. Map LA-UR-02-3916, 25 June 02.

Grieggs, Alison B. (editor). 2001. Cerro Grande; Canyons of Fire, Spirit of Community. University of California and Los Alamos National Laboratory. Published by Los Alamos National Bank, Los Alamos, New Mexico.

Keating, Gordon N., S. Rasmussen and M. Raven. 2002a. Consensus-Building Tools for PostWildfire Geographical Information System (GIS) Design. Los Alamos National Laboratory report. LA-13894-MS.

Keating, Gordon N., P.M. Rich and M.S. Witkowski. 2002b. Challenges for Enterprise GIS in PostWildfire Hazard Mitigation and Emergency Response. Los Alamos National Laboratory technical report. LA-13930-MS.

Keating, Gordon N., P.M. Rich and M.S. Witkowski. 2003. Challenges for Enterprise GIS. Los Alamos National Laboratory report. LA-UR-02-1830. For peer-review publication, in press.

Los Alamos National Laboratory Environmental Surveillance Program. 2002. Environmental Surveillance at Los Alamos during 2001. Los Alamos National Laboratory report. LA-13979ENV.

Los Alamos National Laboratory Newsbulletin. 2002. "New Emergency Operations Center to Rise at Technical Area 69." 8 April 2002 news article.

Mynard, C. Randall and G. N. Keating. 2001. CGRP GIS-Cerro Grande Rehabilitation Project Geographic Information System. Los Alamos National Laboratory publication. LALP-01-173.

National Park Service, Bureau of Land Management, U.S. Forest Service, Department of Energy, and New Mexico Energy, Minerals, and Natural Resources Department. 2000. Investigation Report of the Cerro Grande Prescribed Fire, May 4-8, 2000. 18 May 2000.

ScienceNow. 2002. Bush's Forest Plan Under Fire. Online daily news service. 10 October 2002. U.S. Geological Survey. 1978. Topographic map, 1:100,000 scale. Los Alamos Quadrangle. Webb, M. Diana and K. Carpenter. 2001. The Cerro Grande Fire, Los Alamos, New Mexico. Los Alamos National Laboratory report. LA-UR-01-1630. 
Witkowski, M.S., P.M. Rich, and G.N. Keating. 2002. Spatial data warehouse design for enterprise GIS. In: Proceedings of the GIScience, Second International Conference on Geographic Information Science, Boulder, Colorado, September 25-28, 2002. LA-UR-02-3514.

Witkowski, M.S., P.M. Rich, and G.N. Keating. 2003. Enterprise GIS Design. For peer-review publication, in press.

\subsection{Personal Communications}

Beeson, Peter. 2002. E-mail to C. Randall Mynard, 1 August 2002.

Bolivar, Stephen L. 2000a. Letter of Appreciation for the Santa Fe Map Production Support Team, EES-13-06-00-177, 30 June 2000.

Bolivar, Stephen L. 2002b. E-mail to C. Randall Mynard, 14 June 2002.

Bolivar, Stephen L. 2002c. E-mail to C. Randall Mynard, 12 July 2002.

Canepa, Julie. 2002. E-mail to C. Randall Mynard, 16 August 2002.

Dangermond, Jack. 2002. "Special Achievement in GIS Award." Letter to Paul Rich, 9 May 2002.

Davenhall, Carl S. 2002. Interviews with C. Randall Mynard, 20 May and 18 June 2002.

Gonzales, Richard A. 2002. Interview with C. Randall Mynard, 12 June 2002.

Hart, Orval F. 2002. Update on progress of planning for new LANL EOC information management, presentation to LANL GIS Users Group, 25 October 2001.

Howard, David L. 2002. Interview with C. Randall Mynard, 1 August 2002.

Huchton, John D. 2002. Interview with C. Randall Mynard, 31 July 2002.

Koch, Steven W. 2002. Interview with C. Randall Mynard, 1 August 2002.

Mullen, Kenneth I. 2002. Interview with C. Randall Mynard, 5 August 2002.

Salazar, Harold M. 2002. Interview with C. Randall Mynard, 6 August 2002.

Stockum, Joan L. 2002. Interviews with C. Randall Mynard, 12 June and 5 Aug. 2002.

Valencia, Mona S. 2002. E-mail to C. Randall Mynard, 29 August 2002.

Wilson, Cathy J. 2002. E-mail to C. Randall Mynard, 22 August 2002. 


\subsection{APPENDIX}

\subsection{Special Achievement in GIS Award}

A Special Achievement in GIS (SAG) Award was presented to GISLab, colleagues of Los Alamos National Laboratory and the BAER team on July 11, 2002, in recognition of GIS efforts in support of the Cerro Grande Rehabilitation Project. The award, presented by Environmental Systems Research Institute (ESRI), a leader in GIS technology, was given to select user sites around the world in recognition of their outstanding work in the GIS field. Los Alamos was chosen to receive the prize from over 100,000 user sites worldwide (Dangermond, 2002).

The SAG Award notification letter from Jack Dangermond, President of ESRI, stated the following:

"In May 2000, the Cerro Grande Fire swept through Los Alamos, NM, burning more than 48,000 [43,000] acres, and causing evacuation of the national laboratory and town. GIS was an integral part of response during the fire, and continues to be used for restoration and environmental monitoring under the Cerro Grande Rehabilitation Project. This prize is being awarded to the GISLab (formerly known as FIMAD) and the many colleagues at Los Alamos National Laboratory who contributed to these GIS efforts, and [who] are helping to build a spatial data warehouse for institutional and fire-related spatial data. It should be noted that numerous other groups collaborated in these efforts, including Sandia National Laboratories, Loft4, the Earth Data Analysis Center (EDAC), and the multi-agency Burned Area Emergency Rehabilitation (BAER) team."

Dr. Paul Rich, Team Leader for GISLab, responded as follows:
"The events of May 2000 were extraordinary. The response of the GIS community was equally extraordinary. At one level, everybody was caught unprepared. At another level, the most important preparation was in place: a dedicated community of GIS professionals, skilled at solving problems. These professionals worked together to reconstruct the GIS database, to set up an emergency GIS center in Santa Fe, and to produce maps day and night. GIS efforts have continued in the Cerro Grande Rehabilitation Project. Activities range from floodplain mapping and sediment transport modeling, to planning for forest management, to planning for emergency preparedness, to building a spatial data warehouse for institutional and fire-related spatial data. I am honored, pleased, and humbled to accept this award on behalf of my colleagues: honored because of the recognition, pleased because the recognition is deserved, and humbled because this not an award for one individual, or even one organization, but rather an entire community of dedicated GIS professionals. The cloud of smoke that was the Cerro Grande Fire has a silver lining. That silver lining is the way the GIS community came together during and after the fire." 


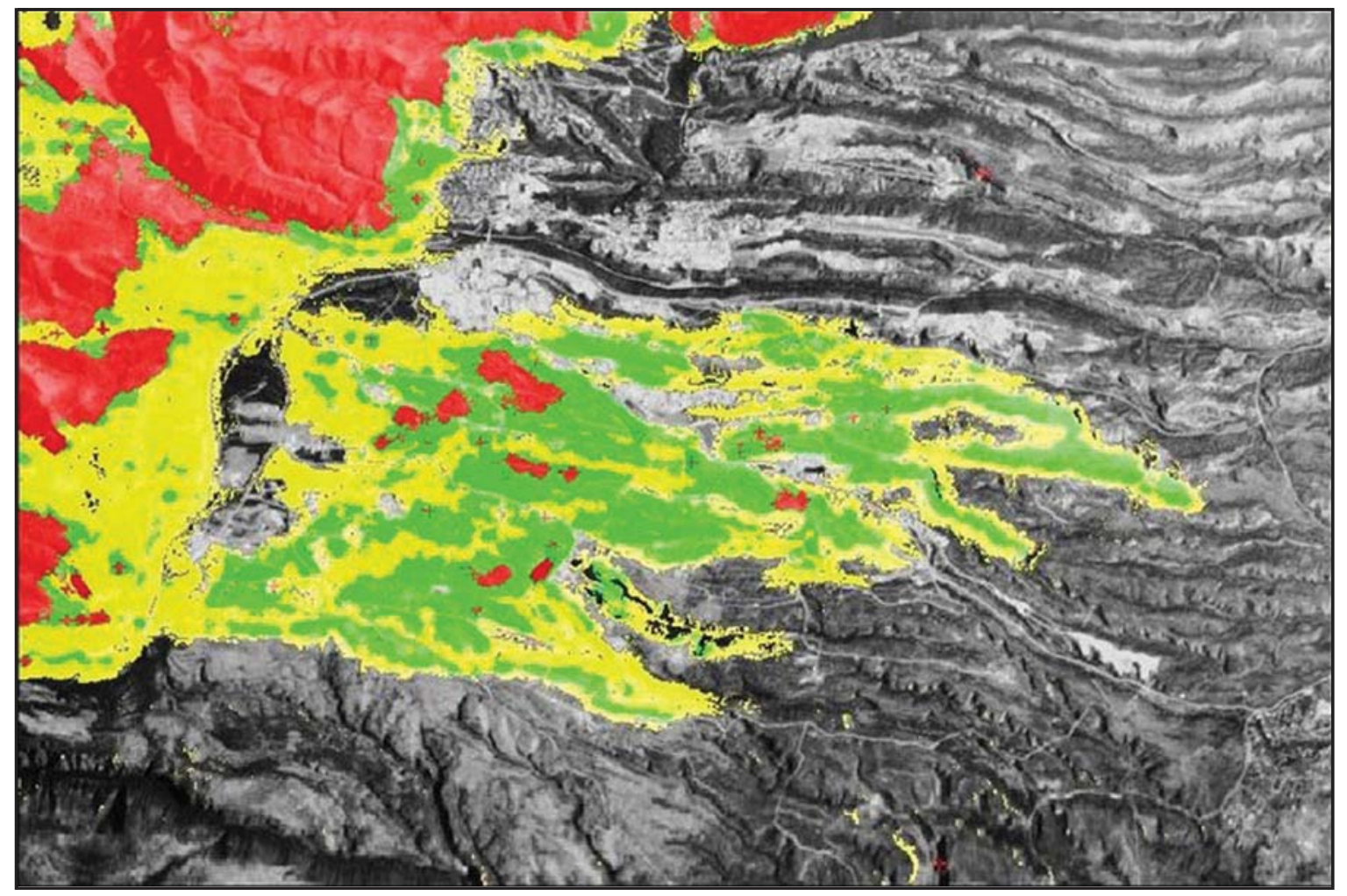

Fig. 44 - Aerial multispectral imagery processed by GENIE (GENetic Imagery Exploitation) technique to reveal relative burn severity of Cerro Grande fire. Red = severe, yellow $=$ moderate, green $=$ light. Burned Los Alamos neigborhoods (yellow and green) are visible at upper center. (Courtesy of Steven P. Brumby, LANL). 
This report has been reproduced directly from the best available copy. It is available electronically on the Web (http://www.doe.gov/bridge).

Copies are available for sale to U.S. Department of Energy employees and contractors from:

Office of Scientific and Technical Information P.O. Box 62

Oak Ridge, TN 37831

(865) 576-8401

Copies are available for sale to the public from: National Technical Information Service

U.S. Department of Commerce

5285 Port Royal Road

Springfield, VA 22616

(800) 553-6847 


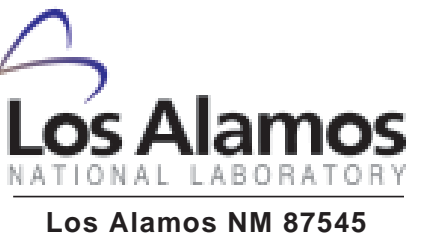

